\title{
ASSESSMENT OF DOSE DURING AN SGTR
}

EGG-NRE--10644

by

DE93 012180

J. P. Adams

Published January 1993

Idaho National Engineering Laboratory

EG\&G Idaho, Inc.

Idaho Falls, ID 83415

\author{
Prepared for the \\ U.S. Nuclear Regulatory Commission \\ Washington, D.C. 20555 \\ Under DOE Contract No. DE-AC07-76ID01570
}

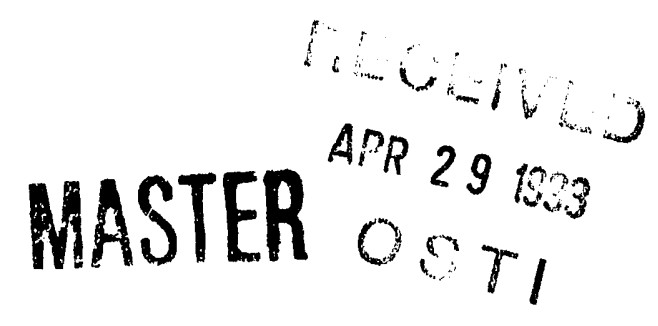




\section{ABSTRACT}

The Nuclear Regulatory Commission requires utilities to determine the response of a pressurized water reactor to a steam generator tube rupture (SGTR) as pa:t of the safety analysis for the plant. The SGTR analysis includes assumptions regarding the iodine concentration in the reactor coolant system (RCS) due to iodine spikes, primary flashing and bypass fractions, and iodine partitioning in the secondary coolant system (SCS). Experimental and analytical investigations have recently been completed wherein these assumptions were tested to determine whether and to what degree they were conservative (that is, whether they result in a calculated iodine source term/dose that is at least as large or larger than that expected during an actual event). The current study has the objective to assess the overall effects of the results of these investigations on the calculated iodine dose to the environment during an SGTR. To assist in this study, a computer program, DOSE, was written. This program uses a simple, non-mechanistic model to calculate the iodine source term to the environment during an SGTR as a function of water mass inventories and flow rates and iodine concentrations in the RCS and SCS. The principal conclusion of this study is that the iodine concentration in the RCS is the dominant parameter, due to the dominance of primary flashing on the iodine source term. 


\section{EXECUTIVE SUMMARY}

The steam generator tube rupture (SGTR) is one of the accident scenarios to be included in the Final Safety Analysis Report (FSAR) of every pressurized water reactor (PWR). The principal concern during an SGTR is the potential release of radioactive iodine from the reactor coolant system (RCS) directly to the environment, bypassing the containment. Several experimental and analytical investigations have been completed recently wherein various SGTR parameters were studied in an attempt to determine whether and to what extent the assumptions used in FSAR analyses of SGTR events are conservative. These parameters include RCS iodine concentration due to an iodine spike, primary bypass, secondary coolant system (SCS) chemistry, and iodine speciation in the SCS. The current study has the objective to assess how the results of these investigations affect the iodine dose to the environment.

A number of simplifying assumptions were made in order that several PWR designs could be included in the study. These assumptions include: complete and instantaneous mixing in the RCS and SCS; steady state water mass flows (both break flow and steam flow) and SCS pH; constant RCS water mass inventory; and a simple model for calculating the dose from the source term. These assumptions were developed into an iodine mass transfer model, forming the basis for a PC-based computer code, DOSE, used in the analysis.

Seven PWR designs were used in this study, Surry 1 and 2, Catawba 1 and 2, Arkansas Nuclear One-Unit 2, D.C. Cook 1 and 2, Palisades, Combustion Engineering CESSAR, and Westinghouse RESAR. Existing thermal and hydraulic data were used to calculate the iodine release to the environment (source term). The source term was then used to calculate the dose to the environment. A series of eight calculations was conducted for each PWR design, corresponding to current Standard Review Plan (SRP) guidelines and varying each parameter in turn and in concert to assess the impact of each on the dose. The dose from each of these calculations was then compared to that corresponding to the base calculation (with SRP guidelines on all parameters). 
In all cases, the principal parameter, in terms of the effect on the dose to the envimnment, was the RCS iodine concentration (i.e. iodine spike). The reason for this preeminence is that the total iodine release was dominated by primary flashing. The effects of changes in the other parameters were negligible by comparison. 


\section{ACKNOWLEDGMENTS}

The author would like to express his thanks to D. L. Hagrman and W. J. Carmack who assisted in the validation of DOSE. Thanks are also due to $\mathrm{J}$. Hopenfeld and J. R. Wolf who contributed to the review of the work. 


\section{CONTENTS}

ABSTRACT ............................

SUMMARY............................ i i

ACKNOWLEDGMENTS $\ldots \ldots \ldots \ldots \ldots \ldots \ldots \ldots \ldots \ldots \ldots \ldots$

INTRODUCTION. ............................. I

DEFINITIONS $\ldots \ldots \ldots \ldots \ldots \ldots \ldots,,,,, \ldots \ldots \ldots \ldots \ldots \ldots \ldots, 4$

METHODOLOGY........................... 6

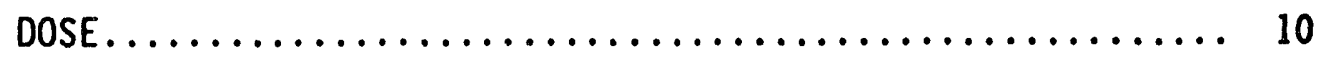

IODINE SOURCE TERM CALCULATIONS ................ 12

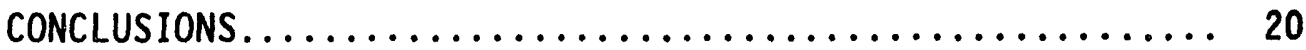

REFERENCES ........................... 21

APPENDIX A. DOSE COMPUTER PROGRAM................

\section{TABLES}

1. DOSE Analysis Results for the Surry 1 and 2 PWRs... 14

2. DOSE Analysis Results for the Palisades PWR...... 14

3. DOSE Analysis Results for the Catawba 1 and 2

PWRs.................................. 15

4. DOSE Analysis Results for the Arkansas Nuclear One Unit 2 PWR.............................. 15

5. DOSE Analysis Results for the D. C. Cook 1 and 2

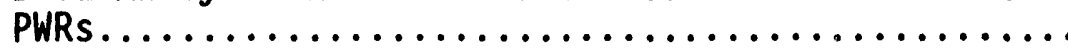

6. DOSE Analysis Results for the Combustion Engineering CESSAR PWR................... 16

7. DOSE Analysis Results for the Westinghouse RESAR PWR................................ 17

8. DOSE Analysis Results for Primary Bypass......... 19

A-1. Source listing of the DOSE computer code........ A-7 A-2. Hand calculation results for Test $1 \ldots \ldots \ldots \ldots$...... 
A-3. Hand calculation results for Test 2............ A-10

A-4. Hand calculation results for Test $3 \ldots \ldots \ldots \ldots . . . . .11$

A-5. Hand calculation results for Test $6 \ldots \ldots \ldots \ldots . . . . .11$

A-6. Hand calculation results for Test $7 \ldots \ldots \ldots \ldots \ldots$ A-12

A-7. Input and output listings for Test $1 \ldots \ldots \ldots \ldots . . .13$

A-8. Input and output listings for Test $2 \ldots \ldots \ldots \ldots . .14$

A-9. Input and output listings for Test $3 \ldots \ldots \ldots \ldots \ldots$ A-15

A-10. Input and output 1 istings for Test $4 \ldots \ldots \ldots \ldots \ldots$ A-16

A-11. Input and output 1istings for Test 5........... A-17

A-12. Input and output 1 istings for Test $6 \ldots \ldots \ldots \ldots . .18$

A-13. Input and output 1istings for Test $7 \ldots \ldots \ldots \ldots$. A-19

A-14. Results from time nodalization sensitivity study... A-20 


\title{
ASSESSMENT OF DOSE DURING AN SGTR
}

\author{
INTRODUCTION
}

In pressurized water reactors, (PWRs), water in the reactor coolant system (RCS) is pressurized to prevent it from boiling. This high-pressure water is circulated through heat exchanger tubes in steam generators where heat is transferred to the lower pressure secondary coolant system (SCS), producing steam that is used to generate elecirical power. The tubes represent a large fraction of the RCS pressure boundary and rupture of these tubes can result in a direct release of radioactivity to the environment (containment bypass) through either the atmospheric dump valves or secondary relief valves. Since this coolant typically contains radioactive materials, a steam generator tube rupture (SGTR) has been designated as a design basis accident for PWRs and must be analyzed as part of the plant's Final Safety Analysis Report (FSAR).

The principal radiological concern during an SGTR results from the presence of radioactive iodine in the RCS coolant. The iodine, a fission product that is present in irradiated fuel, is found in the RCS coolant either as a product of the fissioning of tramp uranium on the fuel element surface or from the fuel itself, being released through tiny holes in the cladding of otherwise undamaged fuel rods. Recent studies have been conducted to determine the amount of radioactive iodine which is expected to be present in the RCS coolant during an SGTR ${ }^{1,2}$. The results from Reference 2 were subsequently modified to account for iodine speciation. ${ }^{3}$ The results of these studies indicate that the RCS coolant iodine concentration during an SGTR with preexisting iodine spike is approximately $11 \mu \mathrm{Ci} / \mathrm{g}$ (contrasted with a value of $60 \mu \mathrm{Ci} / \mathrm{g}$ as specified by the Standard Review Plan ${ }^{4}$ (SRP) for FSAR analyses). The iodine release rate during an SGTR with coincident iodine spike was calculated in Reference 3 to be $1.33 \mathrm{Ci} / \mathrm{h} \cdot \mathrm{MWe}$, which for a $1000 \mathrm{MWe}$ plant is $1330 \mathrm{Ci} / \mathrm{h}$. The SRP specifies the release rate to be 500 times the steady-state release rate, which results in a transient rate typically of the 
order of $25,000-40,000 \mathrm{Ci} / \mathrm{h}$, depending on the plant. Thus, the RCS iodine inventory for either type of SGTR was shown to be much less than that assumed in most FSAR analyses.

During an SGTR, radioactive lodine in the RCS coolant is transported by the break flow from the RCS into the SCS where it is mixed with the other chemicals in the steam generator. If the steam generator secondary is completely filled with water, as a result of the bireak flow, the iodine may be transported, again with water, and released to the environment. However, in the majority of SGTR transients (both postulated and actual), the steam generator is not completely filled and only steam is released to the environment. Therefore, the iodine concentration in the steam must be determined in order to estimate the environmental consequences (i.e. iodine source term to the environment), due to an SGTR.

To address this question (iodine concentration in the steam), two studies were conducted. The first was an experimental study of iodine partitioning between liquid and steam in a closed system under typical operating steam generator thermal/hydraulic conditions. ${ }^{5}$ The sensitivity of iodine partitioning to several parameters was reported for a wide variety of conditions. One of the most important parameters was determined to be the $\mathrm{pH}$ of the coolant. Acidic conditions favor the formation of volatile iodine species and alkaline conditions favor the formation of non-volatile iodine species. Thus, an estimate of the coolant $\mathrm{pH}$ during an SGTR is required for the determination of the iodine partition coefficient and, ultimately, the environmental release of radioactive iodine.

The second was an analytical study wherein the SCS coolant pH during an SGTR was investigated. 6 The $\mathrm{pH}$ was calculated for 10 generic PWR designs, representative of approximately $80 \%$ of the currently operating PWRs in the United States. Due to the wide range of possible chemical concentrations in both the RCS and SCS prior to SGTR initiation, the study was designed to provide a lower bound on the expected $\mathrm{pH}$, resulting in an upper bound on the steam iodine concentration (and, therefore, an upper bound on the iodine source term to the environment). The results of this study indicate that the 
SCS coolant $\mathrm{pH}$ decreases to a value of approximately 6.5 within the first $600 \mathrm{~s}$ of the transient and remains at this value throughout the rest of the transient. This result is independent of reactor design.

The RCS coolant entering the steam generator secondary volume may not completely mix with the SCS coolant. A fraction of the break flow liquid may be carried by the flashing RCS coolant and pass, unmixed, out the steam generator. This is called primary bypass. Westinghouse conducted an experimental investigation to measure primary bypass under several SGTR conditions. ${ }^{7}$ The results of this investigation indicate that primary bypass is negligibly small.

Additionally, part of the RCS break flow which flashes to steam in the secondary (due to the RCS/SCS enthalpy difference) may also pass, unmixed, out of the steam generator. This is called the primary flashing fraction. In many FSAR analyses, it is assumed that all of the break flow which flashes to steam passes, unmixed, out the steam generator. To date, no comprehensive experimental study (similar to that documented in Reference 7 for primary bypass) has been conducted to measure the primary flashing fraction.

Thus, several analytical and experimental studies have been conducted into various aspects of iodine behavior during an SGTR. The purpose of the current study is to assess the overall effects of the results of the earlier analytical and experimental investigations on the calculated iodine dose to the environment during an SGTR. The expected end result is a determination of the relative influence of each parameter (i.e. iodine spike magnitude, partition coefficient, primary flashing fraction, etc.) on the dose to the environment. This report is organized into five parts: to avoid misunderstandings, the principal terms are defined; the analysis methodology is presented, including the assumptions used in the analysis; the analytical tool, a computer program named DOSE, is then described; the specific analyses for several PWRs are then presented, followed by the conciusions of the study. 


\section{DEFINITIONS}

Some confusion may exist regarding the various mechanisms that affect the iodine dose to the environment and that are part of this study. For this reason and at the risk of being redundant, it was decided to reiterate the definitions of these mechanisms as a separate section.

Primary bypass is defined as that fraction of the RCS break flow which remains as a liquid but does not mix with the SCS coolant. Mechanistically, a small fraction of the RCS break flow is entrained with the steam from the flashing RCS coolant and exits the steam generator with the steam. The massbased iodine corizentration in this bypass flow is equal to that of the bulk RCS coolant. Since the primary bypass does not mix with the SCS coolant, its iodine concentration is much higher than that of the steam and a small mass flow results in a disproportionately higher lodine release.

Primary flashing is a thermal/hydraulic phenomena wherein part of the RCS break flow liquid is immediately changed to steam due to the enthalpy difference between RCS and SCS. This occurs at the break location and is a function of the pressure and temperature differences of the RCS and SCS, both of which are functions of time. Mechanistically, as the steam bubbles rise in the SCS coolant, some condensation and/or mixing of the flashed RCS steam could occur. However, the mechanistic treatment of this phenomena is beyond the scope of this study. Therefore, in this study, it was assumed that the mixing and condensation were negligible. Further, it was assumed that the iodine concentration $(\mu \mathrm{Ci} / \mathrm{g})$ in the flashed RCS steam was equal to that of the bulk RCS fluid. As a result, the primary bypass and primary flashing fractions both have the same effect in the DOSE model - namely, carryover of RCS fluid (liquid or steam) mass with a mass-based iodine concentration equal to that of the bulk RCS liquid.

An iodine spike, or transient RCS iodine concentration increase, often occurs due to a power or pressure transient in the primary system. The mechanism whereby this occurs is not precisely understood but is believed to 
be RCS coolant breaching the fuel rod (via pin holes in the otherwise intact cladding) and flushing out a portion of the lodine which is in the claddingfuel pellet gap. If the RCS power/pressure transient occurs prior to initiation of the SGTR, it is called a preexisting iodine spike. If the SGTR itsel $f$ is the cause of the power/pressure transient, it is called a coincident iodine spike.

The iodine partition coefficient, $\mathrm{PC}_{1}$, is defined as the ratio of concentrations of iodine in the liquid and gas phases. Iodine partitions between the steam and liquid phases of a closed aquecus system due to chemical speciation in the liquid. If the chemical thermodynamic conditions favor formation of volatile iodine species (e.g. $I_{2}$ ), more of the iodine partitions into the vapor phase. Conversely, if the thermodynamic conditions favor formation of soluble iodine species (e.g. $\mathrm{I}^{-}$or $\mathrm{IO}_{3}{ }^{\circ}$ ), less of the iodine partitions into the vapor phase. Because the concentration of iodine in the steam phase appears in the denominator of the ratio, low iodine volatility corresponds to large values for $\mathrm{PC}_{1}$ and high iodine volatility, to small values for $\mathrm{PC}_{1}$. Iodine concentration $c$ an be based on the specific water volume (volume-based $\left[\mathrm{Ci} / \mathrm{m}^{3}\right]$ ) or mass (mass-based $[\mathrm{Ci} / \mathrm{kg}]$ ). To avoid confusion with these definitions, except where specifically otherwise noted iodine concentrations will be defined as iodine activity $(C i)$ per unit mass $(\mathrm{kg})$ and the resulting $\mathrm{PC}_{1}$ will be mass-based. This avoids the potential problem of having to account for changes in the SCS steam density (due to SCS pressure changes) with time during the transient.

The purpose of this study was to assess the effects of these parameters on the dose to the environment, not to mechanistically evaluate the parameters themselves. Therefore, all of these phenomena were treated in a nonmechanistic manner and existing values for the individual parameters (iodine spike magnitude, iodine partition coefficient, primary bypass fraction, and primary flashing fraction) were used as input into the DOSE computer program. 


\section{METHODOLOGY}

At the onset of the investigation, it was decided to keep the metiodology as simple as possible so that several PWR designs could be included. To do this, simplifying assumptions were made concerning the thermal and hydraulic boundary conditions during an SGTR:

1. It is assumed that there is complete and instantaneous mixing in the RCS. This has the effect of maintaining a uniform RCS iodine concentration ([I $]_{\text {RCs }}$ ) throughout the transient. There will, obviously, be some degree of incomplete mixing in the RCS during the transient. In the case of an SGTR with preexisting iodine spike, the mixing would have taken place prior to the rupture initiation and would be close to complete due to the effects of pump operation. In the case of an SGTR with coincident iodine spike, the mixing will probably not be complete. However, the iodine concentration will be increasing, due to the continued iodine release from the fuel into the RCS coolant. Since the steam generators are relatively far removed from the core, it is expected that the actual iodine concentration in the break flow will be less than if mixing were instantaneous and complete. Therefore, this assumption (of complete and instantaneous mixing) will result in an upper bound on the mass of iodine transferred into the SCS.

2. With the exception of the break flow which passes, unmixed, out of the steam generator (Primary Bypass and Flashing Fractions), the RCS flow is assumed to mix completely and instantaneously with the SCS coolant. This resultes in 3 uniform SCS iodine concentration ([I $]_{\text {scs }}$ ) throughout the transient. Again, this assumption is not exactly representative of the conditions within the steam generator. Incomplete mixing in the SCS could result in localized regions of high iodine concentration (for example near the tube 
rupture site) which would result in higher iodine concentrations in the vapor. However, there would be other localized regions with smaller than average iodine concentrations which would tend to counteract the higher concentrations resulting in an average vapor concentration near that calculated using this assumption.

3. The SCS coolant $\mathrm{pH}$ is assumed to be constant at a value of 6.5 throughout the transient. This means that the iodine partition coefficient is a constant. This is based on the results documented in Reference 6 wherein it is stated that "...the SCS pH quickly (within $600 \mathrm{~s}$ of transient initiation) decreases from the pre-SGTR value to a value close to that of the RCS (6.5) and then remains nearly constant until transient termination." Prior to the establishment of steady-state conditions, the pH is higher, which results in a smaller vapor iodine concentration. Thus, this assumption results in an upper bound on the iodine release, relative to the actual expected transient.

4. RCS inventory is constant. In the majority of historical steam generator tube leaks and ruptures, the makeup system was adequate to maintain RCS mass inventory. Additionally, for those few cases where the makeup system may not be capable of maintaining RCS inventory (that is, where the break flow rate exceeds the makeup flow rate), the pressurizer will provide an additional source of water to the RCS and this, for most cases, is sufficient to maintain RCS inventory.

5. All flows (RCS break flow and SCS steam rate) are assumed to be constant. The values used in the analysis were the average values over the transient time of $30 \mathrm{~min}$. This assumption may cause some deviation from the expected results (i.e. if the period of maximum break flow does not correspond to the period of maximum [I $]_{\text {Rcs }}$ or if the period of maximum steam mass flow does not correspond to the period of maximum [ $\left.[1]_{\mathrm{scs}}\right)$. However, this is judged to be of second order and should not affect the overall conclusions of the 
study. For example, the period of maximum RCS break flow will be early in the transient. For the case of an SGTR with preexisting iodine spike, where $[\mathrm{I}]_{\mathrm{RCs}}$ is constant, this will make no difference to the iodine transport to the SCS. For the case of an SGTR with coincident iodine spike, the period of maximum break flow occurs when $[1]_{R C S}$ is a minimum and the assumption results in an upper bound on the iodine transported to the SCS. The situation on the secondary side is similar. The steam flow is caused by the steam bubble being "squeezed" by the inflow of RCS coolant, which should be maximized early in the transient since that is the period of maximum RCS break flow. Some delays will, of course, occur since the steam pressure must build up to the relief valve setting, but generally the maximum steam flow will occur prior to maximum [I] $]_{\text {scs. }}$. Therefore, this analysis should result in an upper bound on iodine release to the environment.

6. Ultimately, the result of this study is an assessment of the effects of the various studies on the calculated iodine dose to the enviranment. However, the dose to the environment is calculated using the following equation:

$$
\text { Dose }=\left(B . R_{.}\right) \cdot(\text { L.F. }) \cdot(\mathrm{X} / Q) \cdot(\text { D.C.F. })
$$

where:

$$
\begin{aligned}
\text { B.R. } & =\text { breathing rate = constant } \\
L_{\dot{X}} \cdot \dot{ } & =\text { leakage factor }=\text { iodine release } \\
\mathbf{X} / Q & =\text { dispersion factor = constant } \\
\text { D.C.F. } & =\text { dose conversion factor = constant }
\end{aligned}
$$

Since, in effect, the dose to the environment is a constant (D.C.L. $\mathrm{X} / Q \cdot B . R$.$) times the iodine source term, the relative$ effects of the various studies (i.e. lodine spiking magnitude, 
partition coefficient, primary bypass, etc.) on the dose is identical to the relative effects on the iodine source term.

A simple iodine and water mass balance model was developed and used as the basis for a PC-based computer code, DOSE, described in the next section. A series of SGTR calcu?ations was performed for seven PWR designs using thermal and hydraulic information from individual FSARs as well as other sources. The results from these calculations were compared to determine the relative differences between iodine source terms (environmental doses) for base case calculations (using FSAR assumptions for SGTRs with preexisting and coincident iodine spikes) and those made using the results from recent SGTR studies. 
DOSE

This is a summary of the DOSE computer program, used to calculate the effects of various parameters on the iodine dose during an SGTR. DOSE is a PC-based computer code, written in FORTRAN and compiled by the Lahey FORTRAN compiler F77L, ver. 5.01. All calculations were performed on an IBM PS/2 Model $70 / 386$ personal computer. Each calculation required less than 1 min of computer time to perform.

DOSE calculates the integrated iodine release to the environment during an SGTR. The basis for the code is a mass balance on the iodine as it is released from the fuel to the RCS, is transported from the RCS to the SCS with the break flow, is partitioned to the steam in the SCS, and is transported out of the steam generator with the steam. The assumptions used in the code are discussed in a previous section. Existing thermal and hydraulic information was used, including water mass flow rates and inventories.

The RCS iodine inventory is calculated for a coincident iodine spike using the inventory from the previous time step, modified by the iodine spike release rate (source) and iodine transported to the SCS with the break flow (sink). The RCS iodine concentration is then calculated by dividing the inventory by the (constant) water mass. For the case of a preexisting iodine spike, the RCS iodine concentration is assumed constant at the input value. The break flow is assumed to have the same radioactive iodine concentration as the bulk RCS fluid.

The SCS iodine inventory is calculated using the previous time step SCS iodine inventory, iodine release rate (with the steam) as the sink and break flow-carried iodine as the source (both sink and source are corrected for bypass and/or flashing fractions). The SCS water mass inventory is calculated using the initial inventory, steam mass flow rate as the sink and break flow as the source (both source and sink are corrected for the effects of bypass and flashing). Then, the SCS concentration is calculated and used, in conjunction with the steam mass flow rate and the primary bypass and flashing 
fractions, to calculate the iodine release rate. The iodine release rate, in turn, is integrated to calculate the total iodine release, as a function of time.

The input for the calculations is in NAMELIST format. Examples of input and output decks are shown in Appendix $A$. The interpretation of the input parameters is:

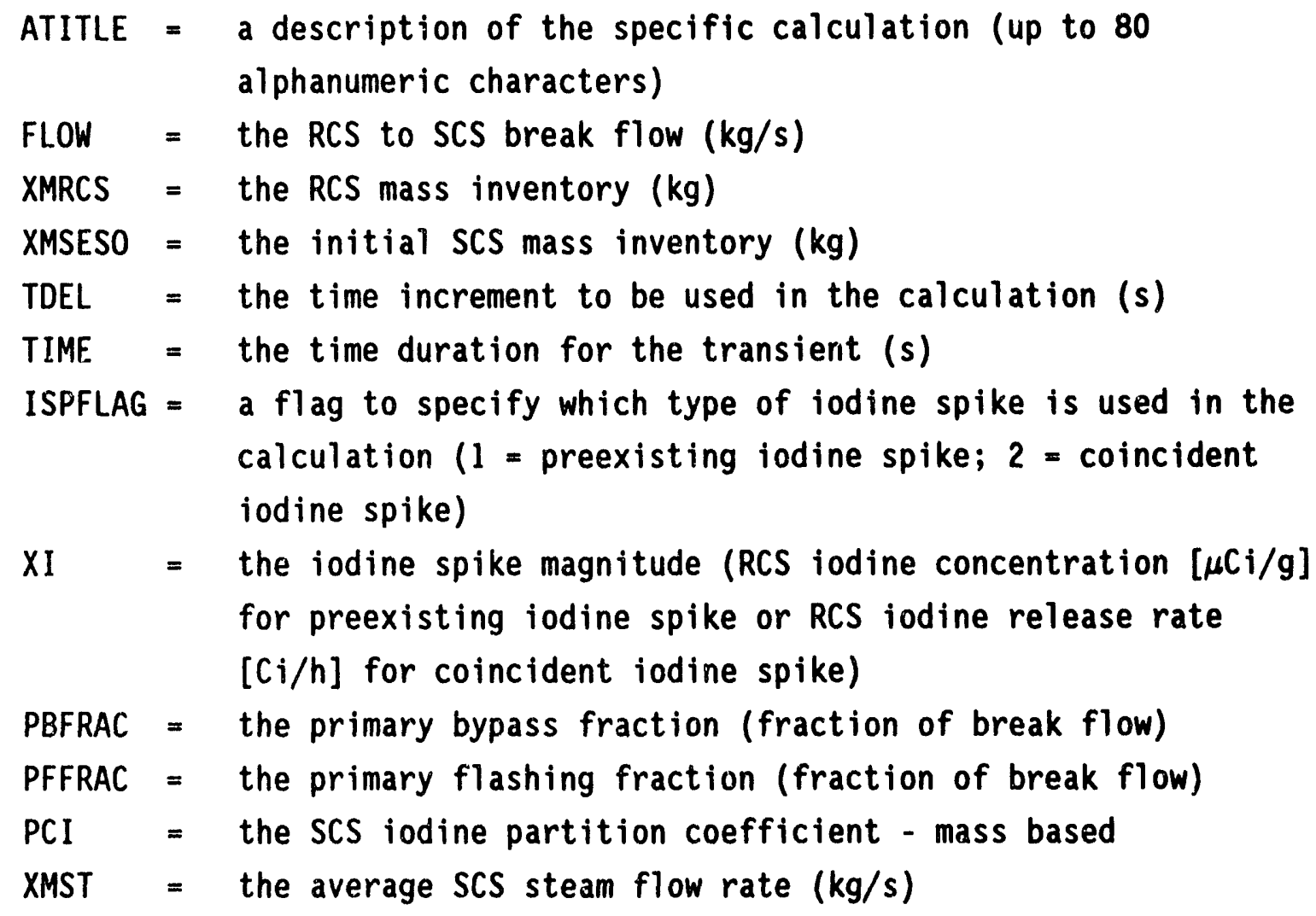

The input is printed as the first part of the output so that the user can verify the calculation. The rest of the output is in tabular format with the following columns: transient time $(\mathrm{s}) ;[\mathrm{I}]_{\mathrm{Rcs}}(\mathrm{Ci} / \mathrm{kg}) ;[\mathrm{I}]_{\text {scs }}(\mathrm{Ci} / \mathrm{kg})$; iodine release rate $(\mathrm{Ci} / \mathrm{s})$; integrated iodine release (iodine source term) ( $\mathrm{C} i$ ); SCS iodine mass inventory $(\mathrm{C} i)$; integrated primary bypass iodine release $(\mathrm{C} i)$; and integrated primary flashing iodine release $(\mathrm{C} i)$. 


\section{IODINE SOURCE TERM CALCULATIONS}

The DOSE computer program, described above and in Appendix $A$, was used to calculate the iodine source term to the environment during an SGTR for seven PWRs. In each case, eight calculations were performed, four for an SGTR with preexisting iodine spike and four for an SGTR with coincident iodine spike.

For the case of an SGTR with preexisting lodine spike, the four calculations used the following assumptions: Calculation 1 : both $[I]_{R C S}$ and $P C_{I}$ based on SRP values $\left([I]_{R C S}=0.060 \mathrm{Ci} / \mathrm{kg}\right.$ and $\left.P C_{1}=100\right) ;$ Calculation 2: [I $]_{\text {RCs }}$ equal to $0.011 \mathrm{Ci} / \mathrm{kg}$ (based on Reference 1) and $P C_{1}$ based on the SRP;

Calculation 3: $[I]_{\text {RCS }}$ based on the SRP and $P C_{1}=272$ (based on References 5 and 6 ); and Calculation 4: [I $]_{R C S}=0.011 \mathrm{Ci} / \mathrm{kg}$ and $P C_{I}=272$.

For the case of an SGTR with coincident iodine spike, the bases for the four calculations are similar: Calculation 1: both $R R_{1}$ and $P C_{1}$ based on the SRP $\left(R R_{1}=500\right.$ times the standardized steady-state value); Calculation $2: R_{1}$ $=1.33 \mathrm{Ci} / \mathrm{s} \cdot$ MWe (based on the results from References 2 and 3 ) and $P C_{1}$ based on the SRP; Calculation 3: $R R_{1}$ based on the $S R P$ and $P C_{1}=272$; and Calculation 4: $R R_{1}=1.33 \mathrm{Ci} / \mathrm{s} \bullet \mathrm{MWe}$ and $P C_{1}=272$.

The values of $0.060 \mathrm{Ci} / \mathrm{kg}$ for $[I]_{R C S}, 100$ for $P C_{1}$, and 500 times the standardized steady-state value for $R_{1}$ are based on the SRP. The value of $0.011 \mathrm{Ci} / \mathrm{kg}$ for $[\mathrm{I}]_{\text {RCs }}$ is based on Reference 1 . The value of $1.33 \mathrm{Ci} / \mathrm{s} \cdot \mathrm{MWe}$ for $R R_{1}$ is based on References 2 and 3 . Both of these values for the iodine spiking magnitude are equal to or greater than the $95 \%$ confidence-90\% probability values.

The experiments reported by Reference 5 included two separate conditions - with and without air (the conditions of no air was accomplished by using an argon overpressure) in the simulated steam generator. The value of 272 for $P C_{1}$ is based on the expected $\mathrm{pH}$ of 6.5 , coupled with the results from Reference 5 for an experiment which excluded air from the simulated steam 
generator. This value was chosen (instead of the value of 37 , which is the value reported in the reference for the experiments made using air) since the presence of oxygen is specifically excluded from operating steam generators by the injection of hydrazene with the secondary feedwater. Thus, it is judged that the $\mathrm{PC}_{1}$ experiments conducted without air in the simulated steam generator more closely match conditions expected to be present in a steam generator during an SGTR. One set of analyses was conducted, however, with the lower value of 37 for $\mathrm{PC}_{1}$, corresponding to the experiments conducted with air, for information. The analysis was made using Surry as the reference plant.

In all calculations, except where specifically otherwise noted, primary bypass was set equal to 0.0 , based on the Westinghouse MB-2 experiments. In all calculations, the primary flashing fraction was set equal to $6.5 \%$, based on representative FSAR calculations from three plants. ${ }^{8}$

The seven plant designs used for this assessment were: Surry 1 and 2, Catawba 1 and 2, Arkansas Nuclear One Unit 2, D. C. Cook 1 and 2, Palisades, Combustion Engineering CESSAR, and Westinghouse RESAR. In all cases except for Surry 1 and 2, the applicable thermal and hydraulic data were extracted from existing FSARs. The information in the Surry FSAR was insufficient for this purpose and so thermal and hydraulic data from an SGTR analysis performed at the INEL were used for this plant. ${ }^{9}$ The specific data required for the analysis were: initial RCS water mass inventory, initial SCS water mass inventory, average break mass flow rate, average steaming rate in the affected steam generator, net MWe for the plant, and purification system flow rate.

Tables 1 - 7 contain the results from these calculations. The dominant parameter, based on these calculations, is the RCS iodine concentration - i.e. iodine spike magnitude. The reduction in iodine spike magnitude resulted in a $80 \%$ reduction in the dose to the environment for the case of a preexisting iodine spike. The reduction ranged between 70 and $95 \%$ for the case of a coincident iodine spike. The effect of an increased partition coefficient (reduced iodine volatility in the SCS coolant) was much smaller and, in many cases, was masked by the effect of the iodine spike. 
Table 1: DOSE Analysis Results for the Surry 1 and 2 PWRs

\begin{tabular}{|l|l|l|}
\hline Calculation & $\begin{array}{l}\text { Relative } \\
\text { Release }\end{array}$ & Remarks \\
\hline 1 & 1.0 & {$[I]_{\text {ecs }}$ and $P C_{1}=S R P$} \\
\hline 2 & 1.0 & $R R_{\text {ecs }}$ and $P C_{1}=S R P$ \\
\hline 3 & .18 & {$[I]_{\text {ecs }}=B E, P C_{1}=S R P$} \\
\hline 4 & .32 & $R R_{\text {ecs }}=B E, P C_{1}=S R P$ \\
\hline 5 & 1.0 & {$[I]_{\text {ecs }}=S R P, P C_{1}=B E$} \\
\hline 6 & 1.0 & {$[I]_{\text {ecs }}=S R P, P C_{1}=37$} \\
\hline 7 & 1.0 & $R R_{\text {ecs }}=S R P, P C_{1}=B E$ \\
\hline 8 & 1.0 & $R R_{\text {ecs }}=S R P, P C_{1}=37$ \\
\hline 9 & .18 & {$[I]_{\text {ecs }}$ and $P C_{1}=B E$} \\
\hline 10 & .18 & {$[I]_{\text {ecs }}=B E, P C_{1}=37$} \\
\hline 11 & .32 & $R R_{\text {Pes }}$ and $P C_{1}=B E$ \\
\hline 12 & .32 & $R R_{\text {ecs }}=B E$ and $P C_{1}=37$ \\
\hline
\end{tabular}

Table 2: DOSE Analysis Results for the Palisades PWR

\begin{tabular}{||l|l|l||}
\hline Calculation & $\begin{array}{l}\text { Relative } \\
\text { Release }\end{array}$ & Remarks \\
\hline 1 & 1.0 & {$[I]_{\text {ecs }}$ and $P C_{1}=S R P$} \\
\hline 2 & 1.0 & $R R_{\text {ecs }}$ and $P C_{1}=S R P$ \\
\hline 3 & .18 & {$[I]_{\text {Res }}=B E, P C_{1}=S R P$} \\
\hline 4 & .03 & $R R_{\text {RCS }}=B E, P C_{1}=S R P$ \\
\hline 5 & .98 & {$[I]_{\text {PCS }}=S R P, P C_{1}=B E$} \\
\hline 6 & .98 & $R R_{\text {PCS }}=S R P, P C_{1}=B E$ \\
\hline 7 & .18 & {$[I]_{\text {PCS }}$ and $P C_{1}=B E$} \\
\hline 8 & .03 & $R R_{\text {PCS }}$ and $P C_{1}=B E$ \\
\hline
\end{tabular}


Table 3: DOSE Analysis Results for the Catawba 1 and 2 PWRs

\begin{tabular}{|c|c|c|}
\hline Calculation & $\begin{array}{l}\text { Relative } \\
\text { Release } \\
\end{array}$ & Remarks \\
\hline 1 & 1.0 & {$[1]_{\text {ecs }}$ and $P C_{1}=S R P$} \\
\hline 2 & 1.0 & $\mathrm{RR}_{\text {ecs }}$ and $P C_{1}=\mathrm{SRP}$ \\
\hline 3 & .18 & {$[1]_{\text {eCS }}=\mathrm{BE}, \mathrm{PC},=\mathrm{SRP}$} \\
\hline 4 & .04 & $\mathrm{RR}_{\mathrm{PCS}}=\mathrm{BE}, \mathrm{PC},=\mathrm{SRP}$ \\
\hline 5 & .98 & {$[1]_{\text {RCS }}=S R P, P C,=B E$} \\
\hline 6 & .98 & $R_{\text {PCS }}=S R P, P C_{1}=B E$ \\
\hline 7 & .18 & {$[1]_{\text {ecs }}$ and $\mathrm{PC}=\mathrm{BE}$} \\
\hline 8 & .04 & $\mathrm{RR}_{\mathrm{PCS}}$ and $\mathrm{PC} C_{1}=\mathrm{BE}$ \\
\hline
\end{tabular}

Table 4: DOSE Analysis Results for the Arkansas Nuclear One Unit 2 PWR

\begin{tabular}{|c|c|c|}
\hline Calculation & $\begin{array}{l}\text { Relative } \\
\text { Release } \\
\end{array}$ & Remarks \\
\hline 1 & 1.0 & {$[I]_{\text {ers }}$ and $P C_{1}=S R P$} \\
\hline 2 & 1.0 & $\mathrm{RR}_{\text {ecs }}$ and $P C_{1}=S R P$ \\
\hline 3 & .18 & {$[I]_{\text {RCS }}=\mathrm{BE}, \mathrm{PC},=\mathrm{SRP}$} \\
\hline 4 & .04 & $R R_{\text {ecs }}=B E, P C_{1}=S R P$ \\
\hline 5 & .98 & {$[I]_{\text {PCS }}=S R P, P C_{1}=B E$} \\
\hline 6 & .98 & $\mathrm{RR}_{\mathrm{PCS}}=\mathrm{SRP}, \mathrm{PC},=\mathrm{BE}$ \\
\hline 7 & .18 & {$[1]_{\text {ecs }}$ and $P C_{1}=B E$} \\
\hline 8 & .04 & $\mathrm{RR}_{\mathrm{PCs}}$ and $\mathrm{PC}=\mathrm{BE}$ \\
\hline
\end{tabular}


Table 5: DOSE Analysis Results for the D. C. Cook 1 and 2 PWRs

\begin{tabular}{||l|l|l|}
\hline Calculation & $\begin{array}{l}\text { Relative } \\
\text { Release }\end{array}$ & Remarks \\
\hline 1 & 1.0 & {$[I]_{\text {Pes }}$ and $P C_{1}=S R P$} \\
\hline 2 & 1.0 & $R R_{\text {ecs }}$ and $P C_{1}=S R P$ \\
\hline 3 & .18 & {$[I]_{\text {ecs }}=B E_{1} P C_{1}=S R P$} \\
\hline 4 & .03 & $R R_{\text {Pes }}=B E, P C_{1}=S R P$ \\
\hline 5 & .99 & {$[I]_{\text {ecs }}=S R P_{1} P C_{1}=B E$} \\
\hline 6 & .99 & $R R_{\text {oes }}=S R P, P C_{1}=B E$ \\
\hline 7 & .18 & {$[I]_{\text {ecs }}$ and $P C_{1}=B E$} \\
\hline 8 & .04 & $R R_{\text {Pes }}$ and $P C_{1}=B E$ \\
\hline
\end{tabular}

Table 6: DOSE Analysis Results for the Combustion Engineering CESSAR PWR

\begin{tabular}{||l|l|l|}
\hline Calculation & $\begin{array}{l}\text { Relative } \\
\text { Release }\end{array}$ & Remarks \\
\hline 1 & 1.0 & {$[I]_{\text {ecs }}$ and $P C_{1}=S R P$} \\
\hline 2 & 1.0 & $R R_{\text {ecs }}$ and $P C_{1}=S R P$ \\
\hline 3 & .18 & {$[I]_{\text {ecs }}=B E, P C_{1}=S R P$} \\
\hline 4 & .05 & $R R_{\text {Pes }}=B E, P C_{1}=S R P$ \\
\hline 5 & .99 & {$[I]_{\text {ecs }}=S R P_{1} P C_{1}=B E$} \\
\hline 6 & .99 & $R R_{\text {PCs }}=S R P, P C_{1}=B E$ \\
\hline 7 & .18 & {$[I]_{\text {ecs }}$ and $P C_{1}=B E$} \\
\hline 8 & .05 & $R R_{\text {PCs }}$ and $P C_{1}=B E$ \\
\hline
\end{tabular}


Table 7: DOSE Analysis Results for the Westinghouse RESAR PWR

\begin{tabular}{|c|c|c|}
\hline Calculation & $\begin{array}{l}\text { Relative } \\
\text { Release } \\
\end{array}$ & Remarks \\
\hline 1 & 1.0 & {$[1]_{\text {ers }}$ and $P C_{1}=S R P$} \\
\hline 2 & 1.0 & $\mathrm{RR}_{\text {ecs }}$ and $P C_{1}=\mathrm{SRP}$ \\
\hline 3 & .18 & {$[1]_{\text {ecs }}=\mathrm{BE}, \mathrm{PC} C_{1}=\mathrm{SRP}$} \\
\hline 4 & .04 & $\mathrm{RR}_{\text {PCS }}=\mathrm{BE}, \mathrm{PC}=\mathrm{SRP}$ \\
\hline 5 & .99 & {$[1]_{\text {ecs }}=S R P, P C_{1}=\mathrm{BE}$} \\
\hline 6 & .99 & $\mathrm{RR}_{\text {PCS }}=\mathrm{SRP}, \mathrm{PC}=\mathrm{I}=\mathrm{BE}$ \\
\hline 7 & .18 & {$[I]_{\mathrm{RCS}}$ and $\mathrm{PC},=\mathrm{BE}$} \\
\hline 8 & .04 & $\mathrm{RR}_{\text {pes }}$ and $P C_{1}=\mathrm{BE}$ \\
\hline
\end{tabular}


The reason that the RCS lodine concentration was the dominant parameter is due to the influence of the primary flashing factor, which in all calculations was set equal to $6.5 \%$ of RCS break mass flow. Nearly all of the activity that was calculated to be released to the environment was due to this factor. This is independent of which PWR design was used in the calculation. This factor is also the one parameter that has not been experimentally studied. Therefore, there is no basis for assuming what degree of mixing or condensation would occur, which could mitigate the effect.

The other parameter of interest in this investigation was the primary bypass fraction. As discussed in the introduction, Westinghouse experimentally investigated primary bypass and concluded that it was negligible. Consequently, current FSAR analyses of the SGTR transient assume zero for this term. ${ }^{10}$ For completeness, a series of 16 calculations was performed to assess the effects of potential primary bypass on the lodine source term. These calculations were made using the Westinghouse RESAR as the PWR design. There were a set of eight calculations for each type of SGTR (with preexisting and with coincident lodine spikes) which followed the same general format as those discussed in the previous paragraph with and without primary bypass. An arbitrary value of $15 \%$ was used for this parameter. Table 8 presents the results of this analysis. The conclusions of this analysis are very similar to that of the other analyses - namely, the biggest effect on the dose to the environment was caused by changes in the RCS iodine concentration, due to the dominant effect of the combined primary bypass and primary flashing fractions. Since these two parameters are treated similarly in DOSE, this is not surprising. The difference between the calculation with and without $15 \%$ primary bypass is generally that the dose to the environment was reduced by approximately $2 / 3$ for the case without bypass. This corresponds closely to the fraction of total unmixed RCS coolant (bypass $=15 \%$ and flashing $=6.5 \%$ ) represented by the primary bypass.

The calculations made using $P C_{1}=37$ (see Table 1) indicate that the change in the dose to the environment is negligible, as was the case with the $P C_{1}=272$. 
Table 8: DOSE Analysis Results for Primary Bypass

\begin{tabular}{|c|c|c|}
\hline Calculation & $\begin{array}{l}\text { Relative } \\
\text { Release }\end{array}$ & Remarks \\
\hline 1 & 1.0 & $\begin{array}{l}{[I]_{\text {RCS }} \text { and } P C_{1}=S R P \text {, Primary Bypass Fraction }} \\
={ }_{15 \%} \text {. }\end{array}$ \\
\hline 2 & 1.0 & $\begin{array}{l}R_{R} R_{S \%} \text { and } P C_{1}=S R P \text {, Primary Bypass Fraction } \\
=15 \% \text {. }\end{array}$ \\
\hline 3 & .17 & $\begin{array}{l}{[I]_{R C S}=B E, P C C_{1}=S R P, \text { Primary Bypass }} \\
\text { Fraction }=15 \% \text {. }\end{array}$ \\
\hline 4 & .04 & $\begin{array}{l}\mathrm{RR}_{\mathrm{RCs}}=\mathrm{BE}, \mathrm{PC}=\mathrm{SRP}, \text { Primary Bypass } \\
\text { Fraction }=15 \% .\end{array}$ \\
\hline 5 & .95 & $\begin{array}{l}{[I]_{\text {RCS }}=S R P, P C_{1}=B E \text {, Primary Bypass }} \\
\text { Fraction }=15 \% .\end{array}$ \\
\hline 6 & 1.00 & $\begin{array}{l}R_{R C s}=S R P, P C=B E, \text { Primary Bypass } \\
F_{\text {raction }}=15 \% \text {. }\end{array}$ \\
\hline 7 & .17 & $\begin{array}{l}{[I]_{\text {BCs }} \text { and } P C_{1}=B E \text {, Primary Bypass Fraction }} \\
=15 \% \text {. }\end{array}$ \\
\hline 8 & .04 & $\begin{array}{l}R_{\text {BCs }} \text { and } P C_{1}=B E \text {, Primary Bypass Fraction }= \\
15 \% \text {. }\end{array}$ \\
\hline 9 & 0.29 & $\begin{array}{l}{[I]_{R C S} \text { and } P C_{1}=S R P \text {, Primary Bypass Fraction }} \\
=0.0\end{array}$ \\
\hline 10 & 0.31 & $\begin{array}{l}R_{R_{\text {gcs }}} \text { and } P C_{1}=S R P, \text { Primary Bypass Fraction } \\
=0.0\end{array}$ \\
\hline 11 & 0.05 & $\begin{array}{l}{[I]_{\text {RCS }}=B E, P C_{I}=S R P, \text { Primary Bypass }} \\
\text { Fraction }=0.0\end{array}$ \\
\hline 12 & 0.01 & $\begin{array}{l}R_{R C s}=B E, P C \\
\text { Fraction }=0.6\end{array}$ \\
\hline 13 & 0.29 & $\begin{array}{l}{[I]_{\text {RCs }}=S R P, P C_{1}=B E, \text { Primary Bypass }} \\
\text { Fraction }=0.0\end{array}$ \\
\hline 14 & 0.30 & $\begin{array}{l}R_{R C s}=S R P, P C C_{1}=B E, \text { Primary Bypass } \\
\text { Fraction }=0.0\end{array}$ \\
\hline 15 & 0.05 & $\begin{array}{l}{[I]_{R C S} \text { and } P C_{1}=B E \text {, Primary Bypass Fraction }} \\
=0.0\end{array}$ \\
\hline 16 & 0.01 & $\begin{array}{l}\mathrm{RR}_{\mathrm{gcs}} \text { and } \mathrm{PC} \mathrm{C}_{1}=\mathrm{BE} \text {, Primary Bypass Fraction }= \\
0.0\end{array}$ \\
\hline
\end{tabular}




\section{CONCLUSIONS}

The effects of primary bypass, iodine spiking, and iodine partition coefficient on the cose to the environment during an SGTR were assessed. DOSE, a simplc, nonmechanistic computer code, was developed for this assessment. Values for the parameters examined in this study were based on research reported uver the past 6 years. The most dominant parameter in this study was clearly the iodine spiking magnitude. Use of recent iodine spiking analyses resulted in a reduction of the iodine dose to the environment of between $80 \%$ and $95 \%$. The reason for this dominance is the assumption of a ccinstant primary flashing fraction of $6.5 \%$, which results in $6.5 \%$ of the RCS break flow exiting the steam generator without mixing with the coolant. The effect due to the iodine partition coefficient was much less, though in the same direction - that is, to reduce the iodine dose to the environment. Since primary bypass is currently not modeled in SGTR analyses (which is consistent with experimental dat; on bypass), the analyses in this study do not differ from current FSAR analyses, in this regard. The effects of primary bypass, if it were modeled, would be identical to that of primary flashing since both are treated similarly in DOSE. One additional analysis used a different, lower, value for the partition coefficient. In this case, the effact on dose was negligible, also due to masking by the effects of iodine spiking magnitude. 


\section{REFERENCES}

1. J. P. Adams, Iodine Spiking Data from Commercial PWR Operations, EGGNERD-8395, 1989.

2. J. P. Adams and C. L. Atwood, Probability of the Iodine Spike Release Rate During an SGTR, EGG-NERD-8648, 1989.

3. Letter from J. P. Adams (INEL) to J. Hopenfeld (USNRC-RES), "Response to Request for Comments on NRR Review of Proposed Resolution of Generic Issue 67.5.1," JPA-11-90, April 15, 1991.

4. U.S.N.R.C. Standard Review Plan, NUREG-0800, Rev. 2, U.S. Nuclear Regulatory Commission, 1981 .

5. E. C. Beahm, et al., Iodine Speciation and Partitioning in PWR Steam Generator Accidents: Final Report, NUREG/CR-5365, ORNL/TM-11168, 1989.

6. J. P. Adams and E. S. Peterson, Steam Generator Secondary pH During a Steam Generator Tube Rupture, EGG-NE-10046, December 1991.

7. Westinghouse Electric Corporation, Coincident Steam Generator Tube Rupture and Stuck-Open Safety Rel ief Valve Carryover Tests (MB-2) Steam Generator Transient Response Test Program, NUREG/CR-4752, March 1987.

8. Personal communications with J. Y. Lee (USNRC-NRR) dated May 13, 1992 August 28, 1992.

9. R. A. Callow, Thermal-Hydraulic Response and Iodine Transport During a Steam Generator Tube Rupture, EGG-EAST-8264, October 1988.

10. Personal communication with J. Y. Lee (U.S.N.R.C. - N.R.R.), dated July 29, 1992, transmitted by JPA-28-92, dated July 29, 1992. 
APPENDIX A

DOSE COMPUTER PROGRAM 
APPENDIX A

DOSE COMPUTER PROGRAM

DOSE is a PC-based computer code, written in FORTRAN and compiled by the Lahey FORTRAN compiler F77L, ver. 5.01. All calculations were performed on an IBM PS/2 Model 70/386. Calculation times were very short, typically less than one minute per calculation.

DOSE calculates the integrated iodine release to the environment during an SGTR. The assumptions used in the code include: complete and instantaneous mixing in both the RCS and SCS; constant (average) break and steam mass flow rates; constant partition coefficient; either preexisting or coincident iodine spike in the RCS; constant RCS mass inventory; and, all primary bypass and flashing fractions flow, unmixed in the SCS, out as part of the steam mass flow. Existing thermal and hydraulic information is used, including water mass flow rates and inventories. DOSE is a non-mechanistic code which relies on correlations for the various input variables.

The RCS iodine inventory is calculated for a coincident iodine spike using the inventory from the previous time step, iodine spike magnitude for release rate, and break flow. The iodine source, for the mass balance, is the iodine release rate, multiplied by the length of the time step. The iodine sink is the break flow mass rate, multiplied by the RCS iodine concentration and the time step. The source and sink are combined with the RCS iodine inventory from the previous time step, which then becomes the value for the current time step. The RCS iodine concentration is then calculated by dividing the inventory by the (constant) water mass. This concentration is used to calculate the iodine source for the SCS and the RCS iodine inventory for the next time step. For the case of a preexisting iodine spike, the RCS iodine concentration is assumed constant at the input value. The break flow is assumed to have the same concentration as the bulk RCS.

The SCS iodine inventory is calculated using the previous time step SCS iodine inventory, iodine release rate (with the steam) as the sink and break flow-carried iodine (less that associated with bypass or flashing fractions) 
as the source. The sink is the steam mass flow rate times the time step times the vapor iodine concentration. The source is the break flow times the RCS iodine concentration times the fraction which mixes in the SCS (1 minus the combined primary bypass and flashing fractions).

The SCS mass inventory is calculated using the initial inventory, steam mass flow rate as the sink and break flow as the source (both source and sink are corrected for bypass and flashing). Then, the SCS concentration is calculated by dividing the SCS iodine concentration by the water mass, and used, in conjunction with the steam mass flow rate and the primary bypass and flashing fractions, to calculate the iodine release rate. The iodine release rate, in turn, is integrated to calculate the total iodine release, as a function of time.

The input for the calculations is in NAMELIST format. The interpretation of the input parameters is:

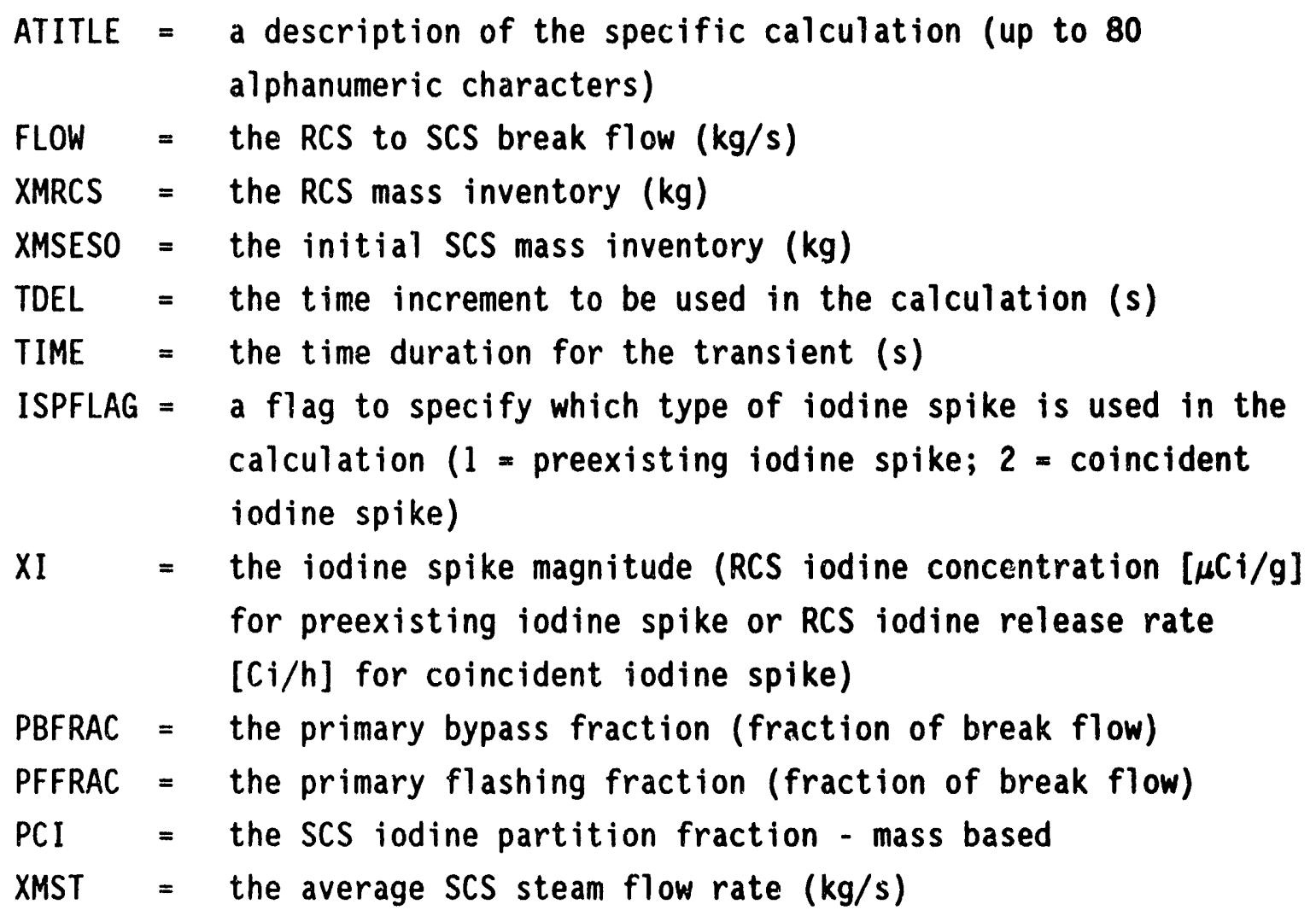


The input is printed as the first part of the output so that the user can verify the calculation. The rest of the output is in tabular format with the following columns: transient time $(\mathrm{s}) ;[\mathrm{I}]_{\mathrm{RCs}}(\mathrm{Ci} / \mathrm{kg}) ;[\mathrm{I}]_{\mathrm{scs}}(\mathrm{Ci} / \mathrm{kg})$; iodine release rate $(\mathrm{Ci} / \mathrm{s})$; integrated iodine release (iodine source term) (Ci); SCS iodine mass inventory ( $\mathrm{Ci}$ ); integrated primary bypass iodine release $(\mathrm{C} i)$; and integrated primary flashing iodine release $(\mathrm{C} i)$.

Table A-1 contains a source listing of the DOSE computer code. After an input deck has been written, it is copied into a file called "DOSE.INP". The program is then run by typing "DOSE2", where the "2" represents the second, or current version of the code. The output is named "DOSE.OUT" and can be copied into any file name chosen by the user. As an efficiency matter, a batch file was written to perform all calculations for a given plant in one batch job. First all of the input files were written and given unique file names. Then, the batch file copied each of the input files, in turn, into the DOSE.INP file and ran the program. The output file was then copied into a file with the same name as the input file but with an "out" extension and the batch program continued with the next input file. This continued until all of the calculations had been performed.

Prior to using DOSE to perform the analysis for this study, seven test cases were designed to verify the coding. These test cases were:

Test 1: Assumed constant $[\mathrm{I}]_{\mathrm{RCS}}=10 \mu \mathrm{Ci} / \mathrm{g}$, break and steaming mass flows $=100 \mathrm{~kg} / \mathrm{s}$, no flashing or bypass, and $P C_{1}=100$. The time increment was set at $10 \mathrm{~s}$. $M_{\mathrm{Rcs}}=10^{5} \mathrm{~kg}$ and $M_{\text {scs }}=10^{4} \mathrm{~kg}$. Three parameters were checked: $[I]_{s c s-1},[I]_{s c s-v}$, and iodine release from the SCS. These values were checked for each of the 6 time steps and are listed in Table A-2.

Test 2: Similar to Test 1 except that a constant $I$ release rate to the $R C S$ was assumed $R R_{1}=10 \mathrm{Ci} / \mathrm{s}$. Parameters checked were $[I]_{s c s}, M_{I-s c s}$, and iodine release. These values were checked for four time steps and are listed in Table A-3. 
Test 3: Similar to Test 1 except that $10 \%$ flashing fraction was assumed. Same parameters were checked for four time steps and are listed in Table A-4.

Test 4: Same as Test 3 except that 10\% bypass, instead of $10 \%$ flashing, was assumed. Same parameters were checked. Since bypass and flashing are treated similarly in DOSE, the results from Test 4 were identical to those from Test 3 - see Table A-4.

Test 5: Same as Tests 3 and 4 except that 5\% flashing and 5\% bypass were modeled. Same parameters were checked. Again, since bypass and flashing are treated similarly in DOSE and since the flashing and bypass add up to a total of $10 \%$ of the break flow, the results from Test 5 are identical to those from Tests 3 and 4.

Test 6: Same as Test 1 except that the steaming mass flow rate was set at $50 \mathrm{~kg} / \mathrm{s}$, or $1 / 2$ that of the break mass flow rate. Only $M_{\text {scs }}$ was checked since the other parameters had previously been evaluated. The SCS mass calculated for each of six time steps is listed in Table A-5.

Test 7: Same as Test 6 except that the primary bypass fraction was set at $10 \%$. Integrated iodine release from the SCS was checked as well as $[I]_{\text {scs }-1}$, and $[I]_{\text {scs-v. }}$. The results are shown in Table A-6 for three time steps.

The input and output listings for these test cases are contained in Tables A-7 - A-13.

All of the test cases were run with the same executable deck. The results from the DOSE calculations were compared with hand calculations for several times steps for each test and all checked out exactly, except for some roundoff errors.

One additional test was conducted to ensure that the time input parameters would not affect the end result. All of the calculations for this 
study were performed with a time step of $10 \mathrm{~s}$ and for a transient duration of $1800 \mathrm{~s}$. The duration was based on typical FSAR calculations. The $10 \mathrm{~s}$ time step was chosen as a compromise to provide adequate detail for the analysis without producing more output than necessary. The 12 calculations using Surry 1 and 2 as the reference plant were redone with a 1 s time step to investigate whether and to what extent the time nodalization would affect the end results. The results of this time nodalization are shown in Table A-14. The maximum difference between calculations made using $10 \mathrm{~s}$ and $1 \mathrm{~s}$ time steps was $3 \%$ for the iodine release in Calculation 8 , which corresponds to SRP values for $[I]_{R C S}$ and $P C_{1}=37$. This is judged to be an adequate level of precision for these calculations.

Thus, it is judged that DOSE has been adequately verified and can be used with confidence, within the limitations of the model. 
Table A-1: Source listing of the DOSE computer code.

PROGRAM DOSE

C THIS IS A BATCH PROGRAM USED TO CALCULATE IODINE DOSE TO THE ENVIRONMENT

C DURING A STEAM GENERATOR TUBE RUPTURE. BOTH COINCIDENT AND PRE-EXISTING

C IODINE SPIKES IN THE RCS CAN BE CALCULATED AND THE SPLIT OF THE IODINE

C IN THE SCS DUE TO BULK SOLUTION, PRIMARY BYPASS AND PRIMARY FLASHING

C ARE ACCOMMODATED. CONSTANT RCS MASS AND INSTANTANEOUS AND COMPLETE

C MIXING

C IN BOTH THE RCS AND SCS ARE ASSUMED. THE PROGRAM WAS WRITTEN USING A

C STANDARD IBM PC EDITOR (KEDIT) AND COMPILED USING LAHEY FORTRAN COMPILER

C F77L VERSION 4.0. USE OF THE EXECUTABLE PROGRAM REQUIRES A MATH

C COPROCESSOR.

C PROGRAMMED BY JAMES P. ADAMS JUNE 18, 1992

C FLOW = LEAK MASS FLOW RATE $(\mathrm{kg} / \mathrm{s})$

C CRCS = RCS CHEMICAL CONCENTRATION (ppm)

C CSCS = SCS CHEMICAL CONCENTRATION (ppm)

C XMRCS $=$ RCS MASS INVENTORY (ASSUMED TO BE CONSTANT) (kg)

C XMSCS $=$ SCS MASS INVENTORY $(\mathrm{kg})$

C $\quad$ XMSCSO = INITIAL SCS MASS INVENTORY $(\mathrm{kg})$

$C$ TDEL = TIME INCREMENT ( $s$ )

C TIME = TIME DURATION OF TRANSIENT (s)

C ISPFLAG $=$ IODINE SPIKE FLAG: $1=$ PRE-EXISTING; $2=$ COINCIDENT

C XI

C PBFRAC

C PFFRAC

= IODINE SPIKE RATE (EITHER $\mu \mathrm{Ci} / \mathrm{g}$ OR $\mathrm{Ci} / \mathrm{h}$ )

C FLUID

C PCI = PARTITION COEFFICIENT - MASS BASED

C XMST = AVERAGE SCS STEAMING RATE $(\mathrm{kg} / \mathrm{s})$

C XIOUT = IODINE MASS RELEASE (Ci)

C VCON = SCS VAPOR IODINE CONCENTRATION $(\mathrm{Ci} / \mathrm{kg})$

C CSCSM = SCS IODINE MASS (Ci)

C

IMPLICIT REAL*8 (A - H)

IMPLICIT REAL*8 (P - Z)

CHARACTER $* 80$ ATITLE

OPEN (UNIT $=7$, FILE $={ }^{\prime}$ DOSE. INP', STATUS $={ }^{\prime}$ OLD')

OPEN (UNIT $=8, F I L E='$ DOSE. OUT', STATUS $=$ ' UNKNOWN')

NAMELIST/INPUT/ATITLE, FLOW, XMRCS, XMSCSO, TDEL, TIME, ISPFLAG, XI, \&PBFRAC, PFFRAC, PCI, XMST

C READ AND WRITE INPUT

C

$\operatorname{READ}(7, N M L=I N P U T)$

WRITE $(8, N M L=$ INPUT $)$

C WRITE OUTPUT HEADER

C

\section{$\operatorname{WRITE}(8,113)$}

113 FORMAT (2X,'TIME', 6X, 'RCS-CONC', 3X, 'SCS-CONC', 5X, 'I-RATE', \&4X, 'I-OUT' , 4X, 'SCS-IMASS' , 2X, 'PB-IMASS' ,3X, 'PF-IMASS') 
Table A-i. (continued)

$c$
$C$
$c$

C CONVERT RCS CONCENTRATIONS FROM $\mu \mathrm{Ci} / \mathrm{g}$ TO $\mathrm{Ci} / \mathrm{kg}$

C OR RCS IODINE RELEASE RATE FROM $\mathrm{Ci} / \mathrm{h}$ TO $\mathrm{Ci} / \mathrm{s}$

C

IF (ISPFLAG.EQ.1) THEN

ELSE

$$
X I C O N C=X I / 1000 \text {. }
$$

ENDIF

$R R I=X I / 3600$.

C SET INITIAL CONDITIONS

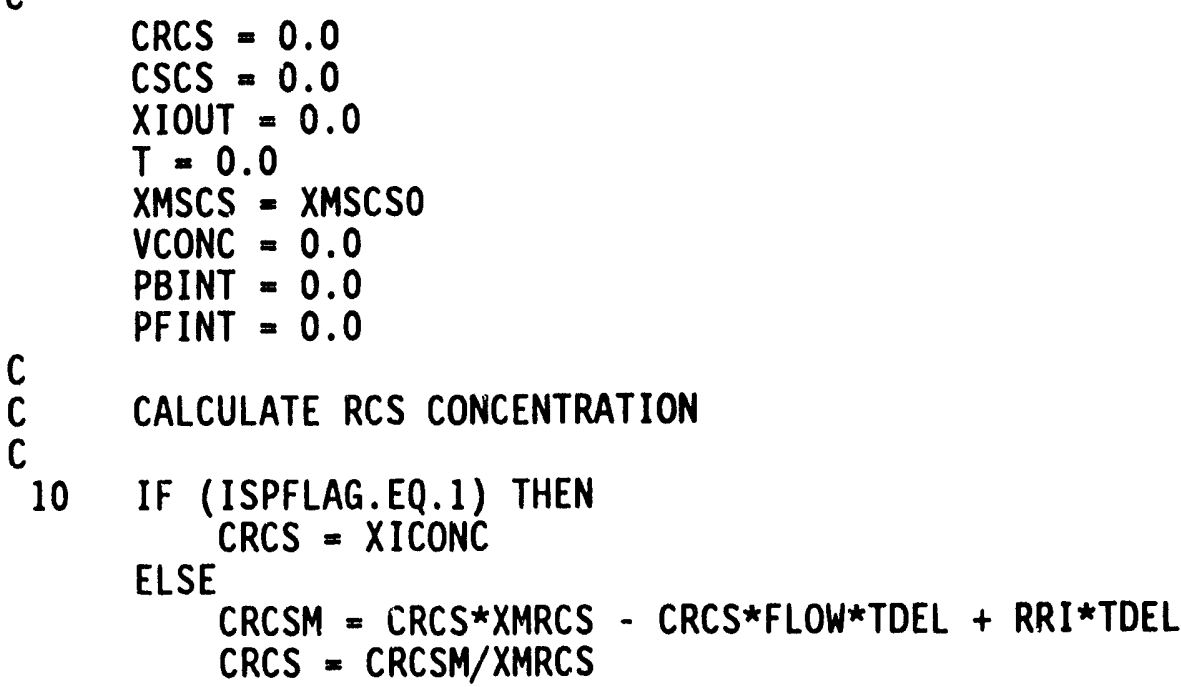

C CALCULATE BULK SCS CONCENTRATION

C $\quad$ CSCSM $=$ CSCS*XMSCS + CRCS*FLOW*TDEL* $(1.0-$ PBFRAC - PFFRAC $)$

\& - VCONC*TDEL*(XMST - FLOW*(PBFRAC + PFFRAC))

$X M S C S=X M S C S+F L O W * T D E L *(1.0-$ PBFRAC - PFFRAC $)$

XMSCS $=$ XMSCS - TDEL* $(X M S T-F L O W *(P B F R A C+$ PFFRAC $))$

CSCS $=\operatorname{CSCSM} / X M S C S$

C CALCULATE STEAM IODINE CONCENTRATION

C

C

VCONC $=$ CSCS $/ P C I$

C CALCULATE IODINE RELEASE RATE FROM SCS

C

XMFLO $=$ XMST - FLOW (PBFRAC + PFFRAC)

$X I F L O W=V C O N C * X M F L O$

$B P F L O W=F L O W^{*} C R C S^{*}($ PBFRAC + PFFRAC)

PBFLOW $=$ FLOW*CRCS*PBFRAC

PBINT = PBINT + PBFLOW*TDEL

PFFLOW $=$ FLOW*CRCS*PFFRAC 
Table A-1. (continued)

PFINT = PFINT + PFFLOW*TDEL

$X I F L=X I F L O W+B P F L O W$

c $X I O U T=X I O U T+X I F L * T D E L$

C UPDATE TIME

C $T=T+$ TDEL

C WRITE TO OUTPUT FILE

C

WRITE $(8,114) T$, CRCS, CSCS, XIFL, XIOUT , CSCSM, PBINT, PF INT

$114 \operatorname{FORMAT}(8(E 10.4,1 X))$

C

C CHECK FOR END OF TRANSIENT

C

IF (T.LE.TIME) GOTO 10

CONTINUE

STOP

END 
Table A-2: Hand calculation results for Test 1.

\begin{tabular}{||l|l|l|l||}
\hline $\begin{array}{l}\text { Time } \\
(s)\end{array}$ & $\begin{array}{l}{[I]_{s s s-}} \\
(C i / k g)\end{array}$ & $\begin{array}{l}{[I]_{s s s-y}} \\
(C \mathrm{i} / \mathrm{kg})\end{array}$ & $\begin{array}{l}\text { I- out } \\
(C i)\end{array}$ \\
\hline 0 & 0 & 0 & 0 \\
\hline 10 & $1.0 \mathrm{e}-3$ & $1.0 \mathrm{e}-5$ & $1.0 \mathrm{e}-2$ \\
\hline 20 & $1.999 \mathrm{e}-3$ & $1.999 \mathrm{e}-5$ & $2.999 \mathrm{e}-2$ \\
\hline 30 & $2.997 \mathrm{e}-3$ & $2.997 \mathrm{e}-5$ & $5.996 \mathrm{e}-2$ \\
\hline 40 & $3.994 \mathrm{e}-3$ & $3.994 \mathrm{e}-5$ & $9.99 \mathrm{e}-2$ \\
\hline 50 & $4.99 \mathrm{e}-3$ & $4.99 \mathrm{e}-5$ & $1.498 \mathrm{e}-1$ \\
\hline
\end{tabular}

Table A-3: Hand calculation results for Test 2.

\begin{tabular}{||l|l|l|l|}
\hline \hline $\begin{array}{l}\text { Time } \\
(\mathrm{s})\end{array}$ & $\begin{array}{l}{[I]_{\mathrm{ss}-}} \\
(\mathrm{i} / \mathrm{kg})\end{array}$ & $\begin{array}{l}{[I]_{\mathrm{ss}}-\mathrm{y}} \\
(\mathrm{Ci} / \mathrm{kg})\end{array}$ & $\begin{array}{l}\mathrm{I} \text { - out } \\
(\mathrm{Ci})\end{array}$ \\
\hline 0 & 0 & 0 & 0 \\
\hline 10 & $1.0 \mathrm{e}-4$ & $1.0 \mathrm{e}-6$ & $1.0 \mathrm{e}-3$ \\
\hline 20 & $2.989 \mathrm{e}-4$ & $2.989 \mathrm{e}-6$ & $3.989 \mathrm{e}-3$ \\
\hline 30 & $5.956 \mathrm{e}-4$ & $5.965 \mathrm{e}-6$ & $9.945 \mathrm{e}-3$ \\
\hline
\end{tabular}


Table A-4: Hand calculation results for Test 3.

\begin{tabular}{||l|l|l|l||}
\hline $\begin{array}{l}\text { Time } \\
(\mathrm{s})\end{array}$ & $\begin{array}{l}{[\mathrm{I}]_{\mathrm{sss}}} \\
(\mathrm{Ci} / \mathrm{kg})\end{array}$ & $\begin{array}{l}{[1]_{\mathrm{sss}}} \\
(\mathrm{Ci} / \mathrm{kg})\end{array}$ & $\begin{array}{l}1-\text { out } \\
(\mathrm{Ci})\end{array}$ \\
\hline 0 & 0 & 0 & 0 \\
\hline 10 & $9.0 \mathrm{e}-4$ & $9.0 \mathrm{e}-6$ & 1.0081 \\
\hline 20 & $1.799 \mathrm{e}-3$ & $1.799 \mathrm{e}-5$ & 2.024 \\
\hline 30 & $2.697 \mathrm{e}-3$ & $2.697 \mathrm{e}-5$ & 3.048 \\
\hline
\end{tabular}

Table A-5: Hand calculation results for Test 6.

\begin{tabular}{||l|l|}
\hline Time $(s)$ & $M_{\text {scs }}(\mathrm{kg})$ \\
\hline 0 & $1.0 \mathrm{e} 4$ \\
\hline 10 & $1.05 \mathrm{e} 4$ \\
\hline 20 & $1.1 \mathrm{e} 4$ \\
\hline 30 & $1.15 \mathrm{e} 4$ \\
\hline 40 & $1.2 \mathrm{e} 4$ \\
\hline 50 & $1.25 \mathrm{e} 4$ \\
\hline
\end{tabular}


Table A-6: Hand calculation results for Test 7.

\begin{tabular}{||l|l|l|l|}
\hline $\begin{array}{l}T \text { ime } \\
(\mathrm{s})\end{array}$ & $\begin{array}{l}{[I]_{\mathrm{sgs}}} \\
(\mathrm{Ci} / \mathrm{kg})\end{array}$ & $\begin{array}{l}{[\mathrm{I}]_{\mathrm{ss}-\mathrm{s}}} \\
(\mathrm{Ci} / \mathrm{kg})\end{array}$ & $\begin{array}{l}\mathrm{I} \text {-out } \\
(\mathrm{Ci})\end{array}$ \\
\hline 0 & 0 & 0 & 0 \\
\hline 10 & $8.571 \mathrm{e}-4$ & $1.714 \mathrm{e}-5$ & 1.00686 \\
\hline 20 & $1.636 \mathrm{e}-3$ & $3.271 \mathrm{e}-5$ & 2.020 \\
\hline
\end{tabular}




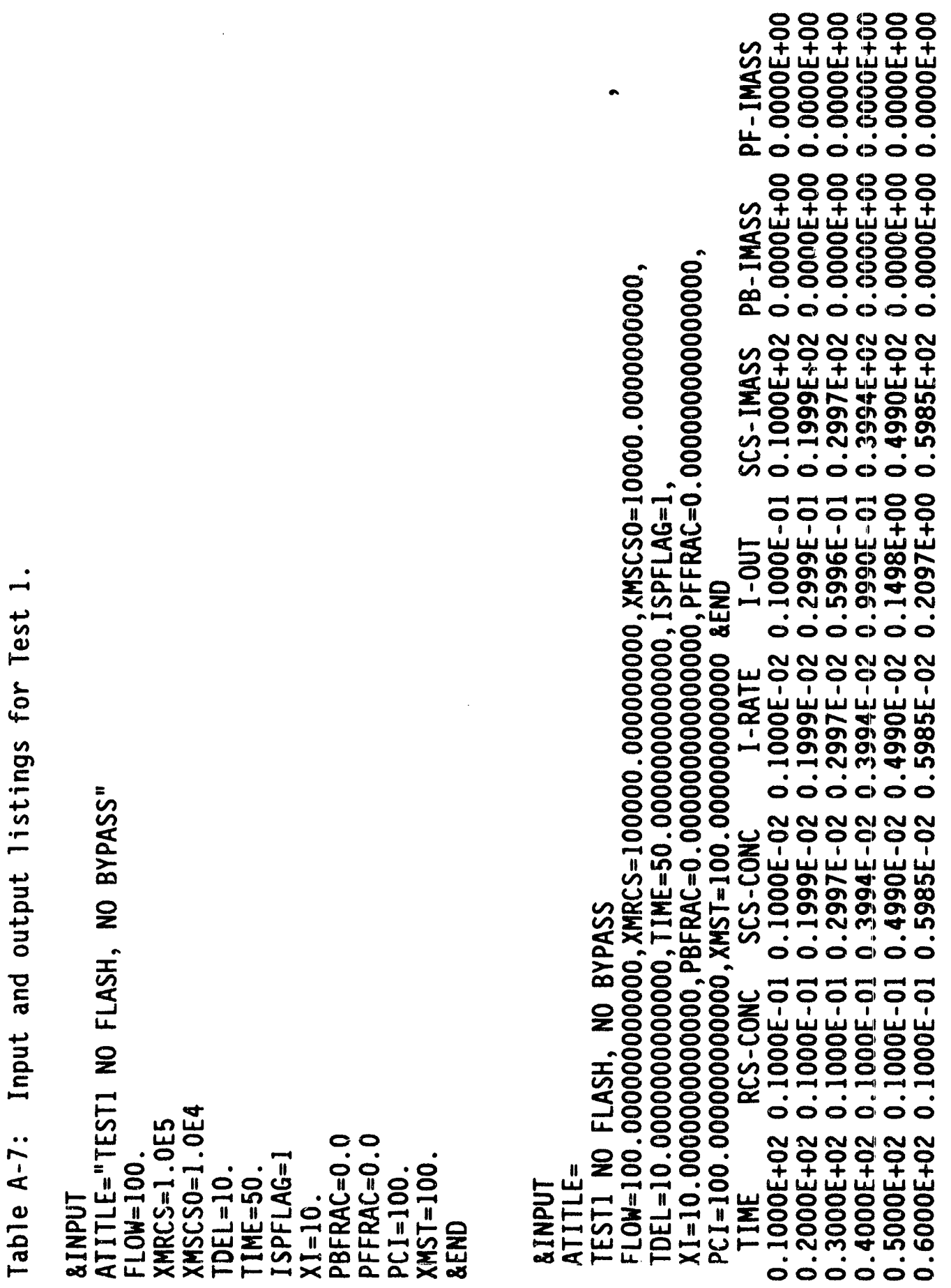




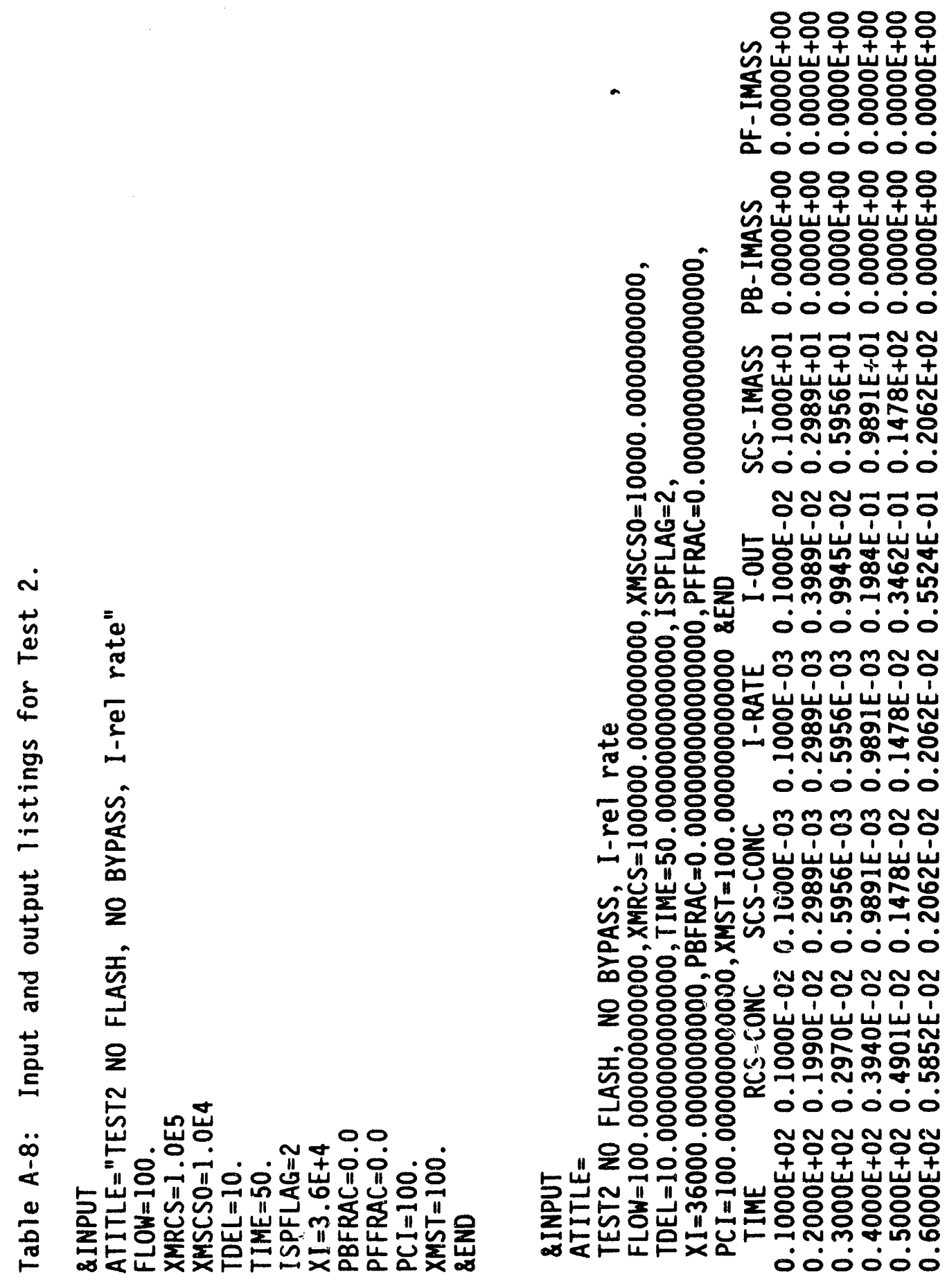




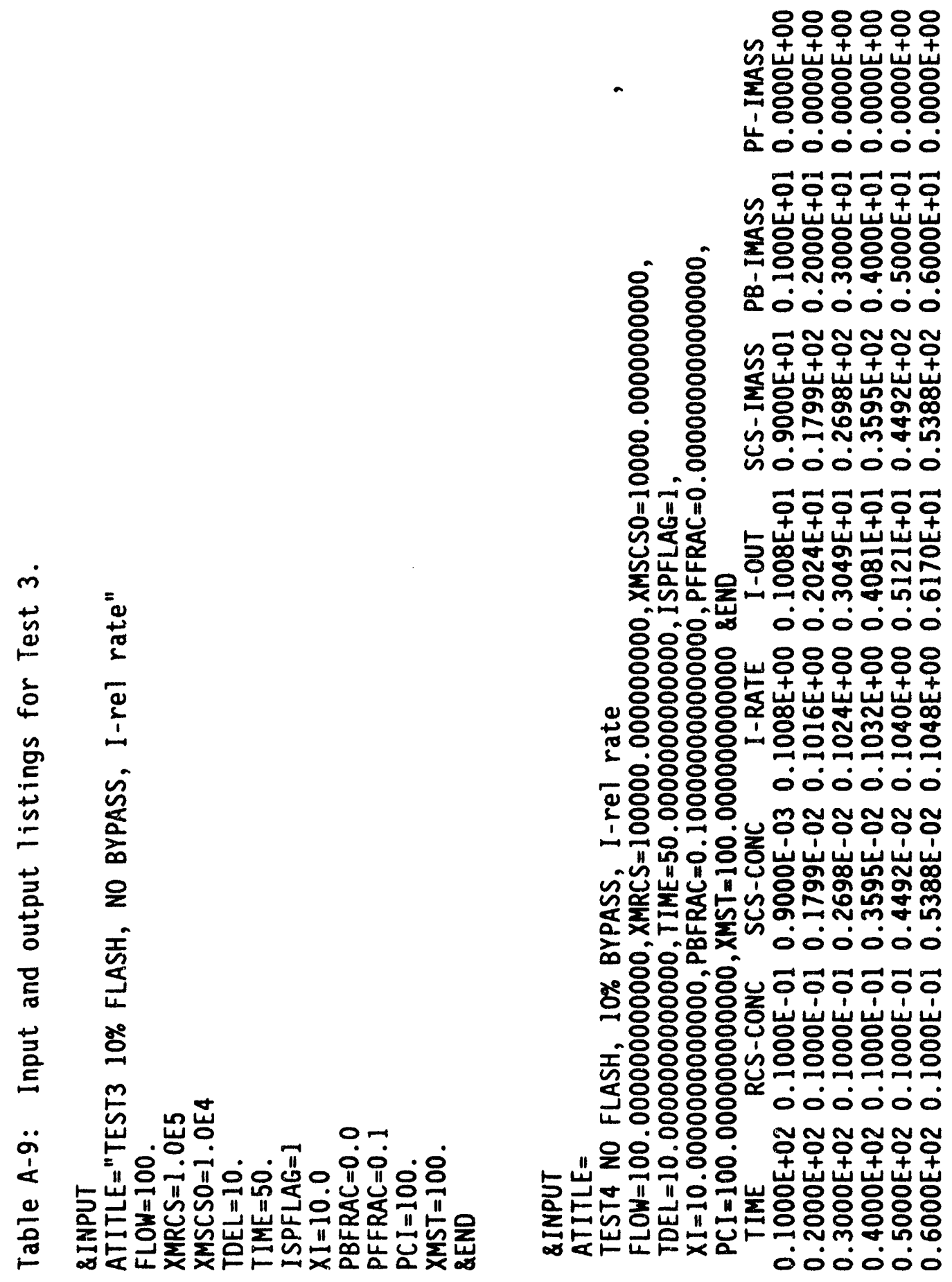




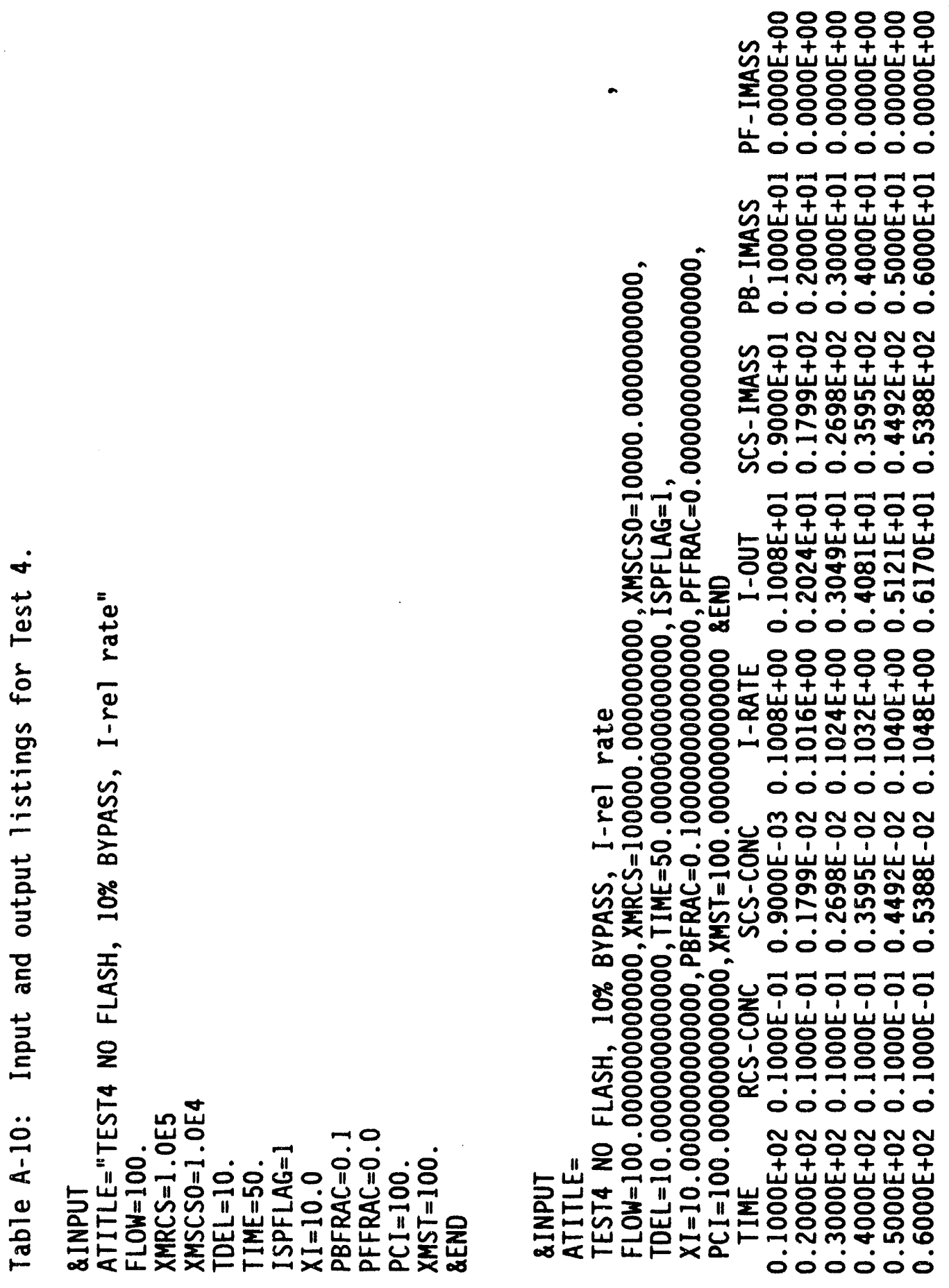




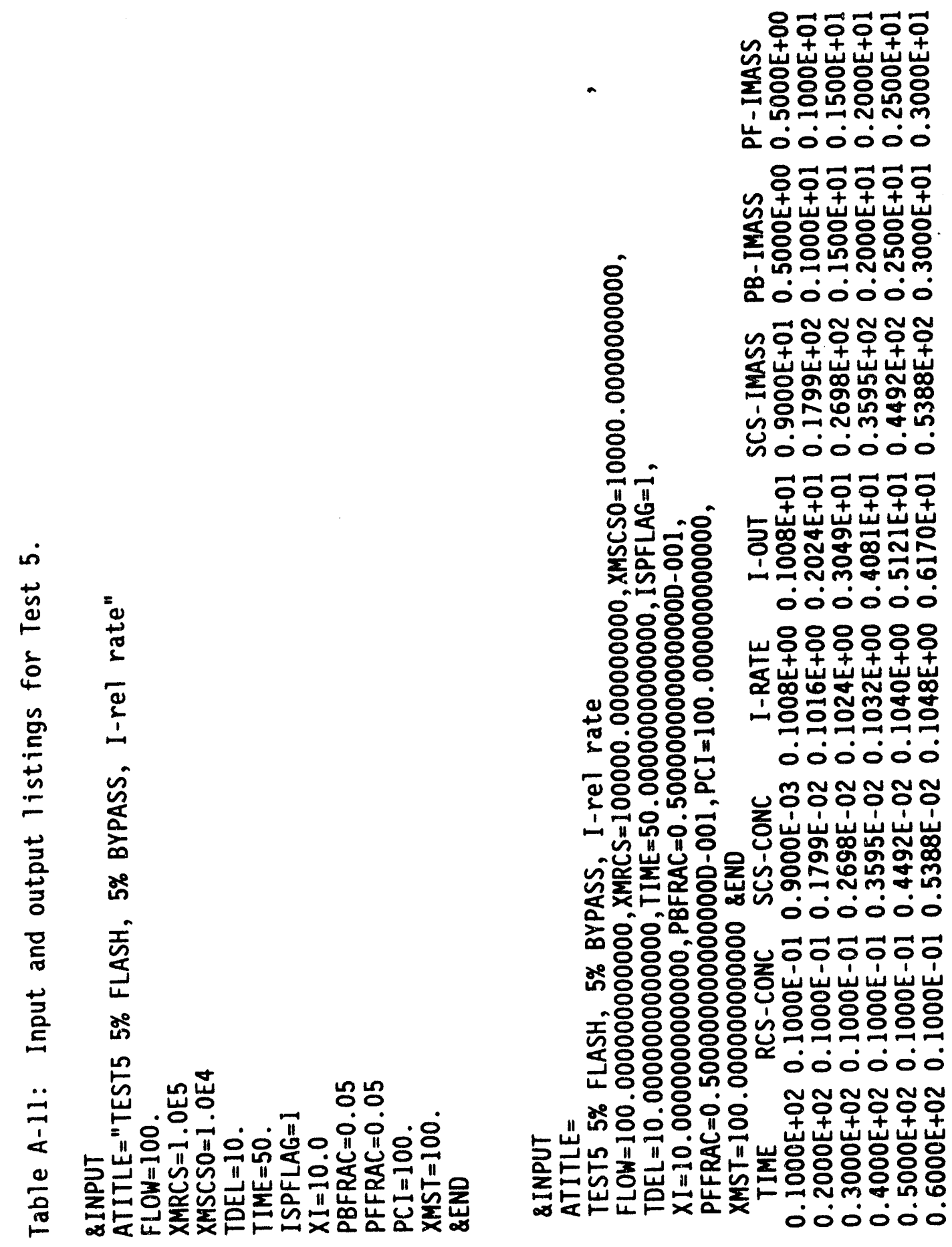




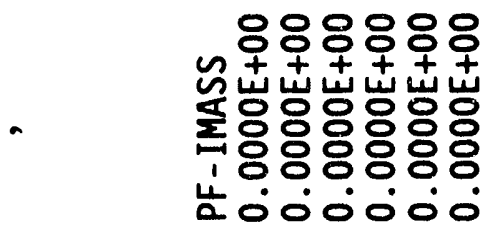

8088808 n $4+4++1$

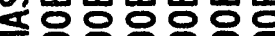

용 향융ㅇㅇㅇ융

\& 용 \&000்0ं 8ㅇ

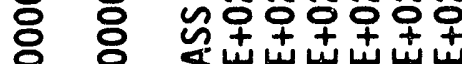
ㅇㅇㅇ 종ㄴㅇㅇ년 ○ 8 용요영 ㅇㅇㅇ ท่유윴용

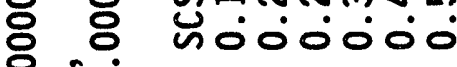
퓨유 웅훙ㅎㅇㅎㅇㅇ 路 过

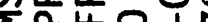

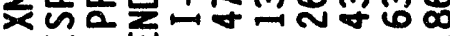
ర์ 000000 융ㅇㅇㅇㅢ m $\sim$ พ ㅇㅇㅇㅇㅇㅇ은ㅇㅇㅇㅇㅇㅇㅇ 8888ㄷํㄴ

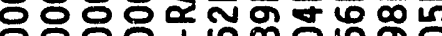
ㅇㅇㅇㅇㅁㄴㅇㅇ요용

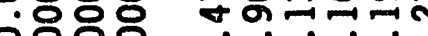
ㅇㅇㅇㅇ 000000

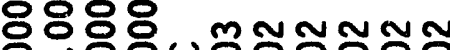
ㅇㅇㅇ웡ㅇㅇㅇㅇㅇㅇㅇㅇ

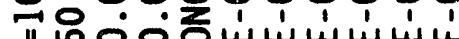

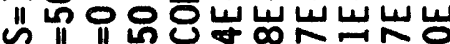

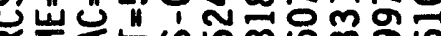

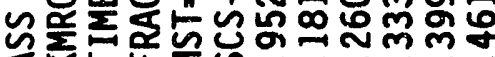

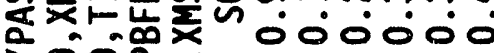

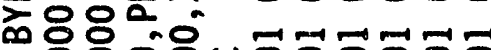

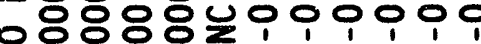
웅ㅇㅇㅇㅇㅇㅇㅇㅇㄴ

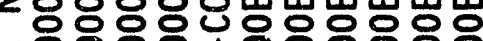
잉ㅇㅇㅇ잉ㅇㅇㅇㅇㅇ응응

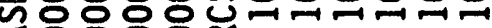

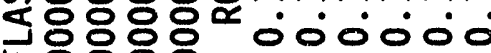
ᄂ잉ㅇㅇㅇㅇㅇㅇ

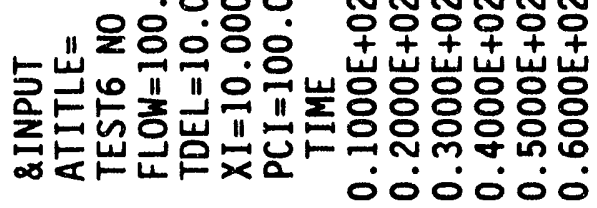




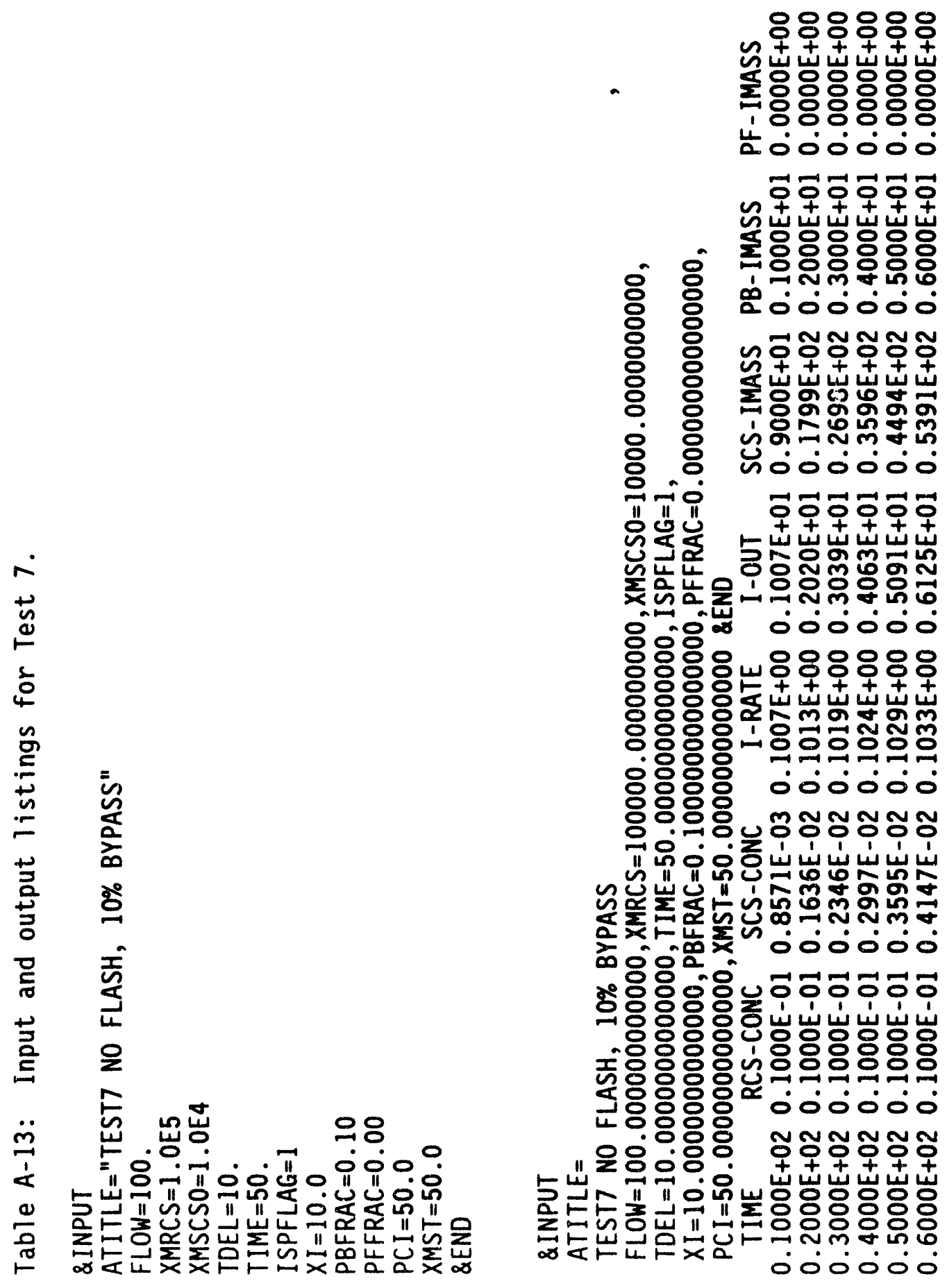




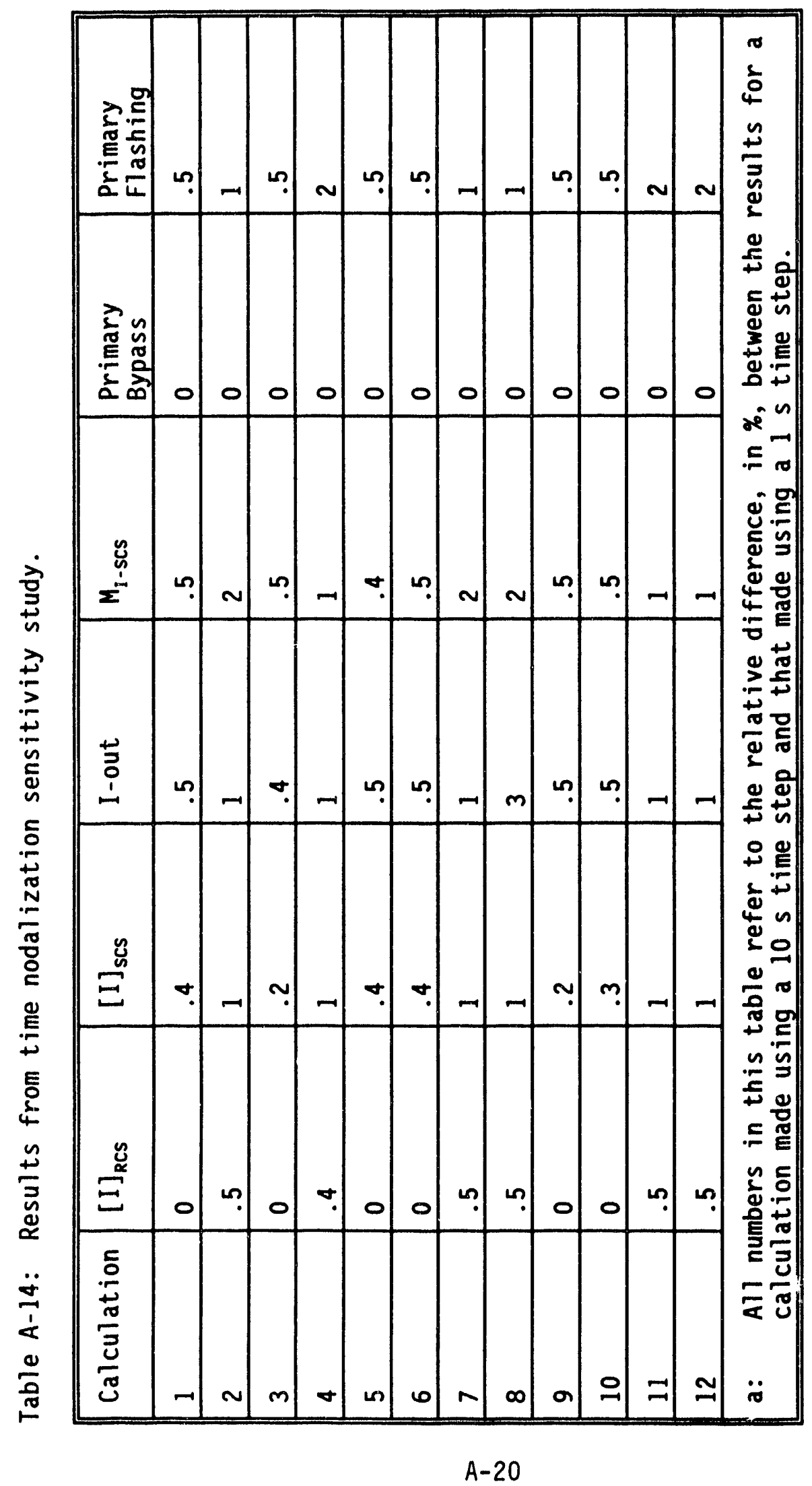



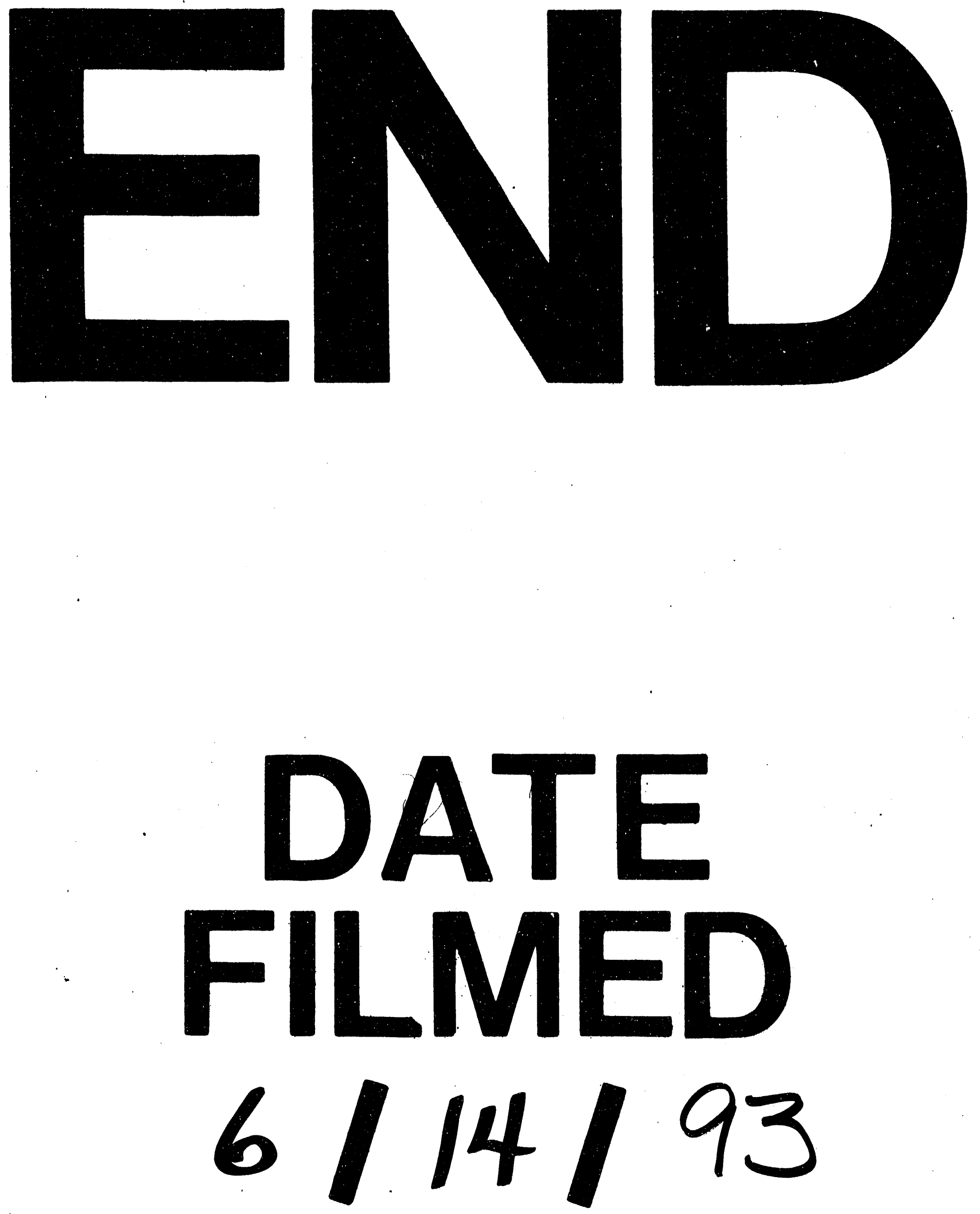
